\title{
IDEOLOGICAL POLARIZATION, STICKY INFORMATION, AND POLICY REFORMS
}

\author{
TOMER BLUMKIN \\ VOLKER GROSSMANN
}

CESIFO WORKING PAPER NO. 1274

CATEgory 2: Public CHOICE

SEPTEMBER 2004

An electronic version of the paper may be downloaded

- from the SSRN website:

http://SSRN.com/abstract $=601601$

- from the CESifo website:

www.CESifo.de 


\title{
IDEOLOGICAL POLARIZATION, STICKY INFORMATION, AND POLICY REFORMS
}

\begin{abstract}
We develop a dynamic two-party political economy framework, in which parties seek to maximize vote share and face the trade-off between catering to their respective core constituencies on the one hand and 'middle of the road' voters with no partisan affiliation on the other hand. In contrast to ideology-driven individuals, 'middle of the road' voters care about the state of the economy in the sense that a policy reform is desirable for them when the fundamentals of the economy change. However, information is "sticky" in the sense that the process of information diffusion about the state of the economy, which is determined by some exogenous stochastic process, is imperfect. Contrary to conventional wisdom, we show that an increase in ideological polarization may enhance social welfare by mitigating the friction in information flow.
\end{abstract}

JEL classification: D72, D80, H30.

Keywords: ideological polarization, sticky information, partisanship, policy reform.

\author{
Tomer Blumkin \\ Department of Economics \\ Ben-Gurion University of the Negev \\ Beer-Sheva 84105 \\ Israel \\ tomerblu@bgumail.bgu.ac.il
}

\author{
Volker Grossmann \\ Socioeconomic Institute \\ University of Zurich \\ Zürichbergstr. 14 \\ CH-8032 Zurich \\ Switzerland \\ volker.grossmann@wwi.unizh.ch
}

We are grateful to Alex Cukierman, Josef Falkinger, Hans-Peter Grüner and Assaf Razin for helpful comments and discussions. We also wish to thank seminar participants at the Silvaplana workshop in Political Economy, and research seminars at Tel Aviv University, Ben-Gurion University and Ifo Institute Munich for valuable suggestions. 


\section{Introduction}

The fact that socially desirable policy reforms are often not adopted or substantially delayed is indicative of the divergence between the benevolent social planner models, the mainstay of traditional public economics literature, suggesting that reforms should be immediately implemented with the prospect of a gain in social welfare, and realworld economics. The political economy literature has attempted to provide a rational explanation for these ostensibly irrational patterns of policy decision making. The key premises on which the literature dwells heavily are the existence of influential vested interest groups ${ }^{1}$ and incomplete (and/or asymmetric) information regarding the costs and benefits entailed by the policy reform at stake. ${ }^{2}$

As argued by Drazen (2000), perhaps the most influential vested interests are politicians, whose primary objective is to gain political power (e.g., by getting elected or by increasing their vote share), a goal generally not coinciding with social welfare maximization. Politicians are often described as being driven not only by power hunger but also by other factors such as ideology. One way to think about the ideological motive is parties' loyalty to their core constituencies. In a sense, thinking of ideology in these terms suggests that parties are in fact driven by power hunger but account for ideology to the extent that they care about the potential vote share of their partisans whose political affiliation is shaped by their ideology. Indeed there is evi-

\footnotetext{
${ }^{1}$ The role of interest groups (the argument is often associated with Olson, 1982) relates to the relevance of the existence of powerful groups blocking any attempt to adopt reforms that imperil their narrow economic advantages, as an explanation for non-adoption of policy reforms from which the society at large stands to gain. For further developments on the economics of special interest groups, see, e.g., Grossman and Helpman (1996, 2001).

${ }^{2}$ For example, Fernandez and Rodrik (1991) show that when individual benefits associated with a certain policy reform are (ex-ante) uncertain and non-insurable, it may well be the case that a reform desirable from an ex-post point of view of the majority of the electorate is nonetheless opposed, thus rejected by a majority of the voters ex-ante. Another example for the role of imperfect information in blocking a socially desirable policy reform concerns scenarios in which the policymaker is better informed than the electorate regarding the state of the world, hence the desirable policy to implement. But nonetheless, due to conflicting objectives, he fails to credibly communicate this knowledge to the voters, and hence fails to implement a socially desirable policy. The idea is explored in Cukierman and Tommasi (1998a, 1998b) who show that a leftwing (rightwing, respectively) party might fail to implement a leftwing (rightwing, respectively) socially desirable policy, because the electorate suspects the proposal derives from partisan (ideological) motives rather than the benefit of the voters themselves.
} 
dence indicating the ideological predispositions of a considerable part of the electorate. As Tab. 1 shows, in 2000, a total share of around 7 percent of the U.S. population who put themselves on the standard seven-point scale identified themselves as extremely liberal ('Left') or extremely conservative ('Right'), ${ }^{3}$ and around 46 percent reported a clear position as liberal or conservative - albeit not necessarily being an extreme one. There is further evidence indicating that ideological preferences ultimately shape partisanship (see e.g. Abramowitz and Saunders, 1998, and Schreckhise and Shields, 2003). As Tab. 1 shows, around one-third strongly identify with either the Democrats or Republicans, and two-thirds show at least a clear affiliation.

Table 1: Ideology and party identifiers in the U.S. in 2000.

$\begin{array}{lllll}\text { in percent } & \text { Extreme Left } & \text { Clear Left } & \text { Extreme Right } & \text { Clear Right } \\ \text { Ideology } & 1.9 & 16.4 & 5.2 & 30.5 \\ \text { Party Identification } & 15.9 & 32.1 & 17.8 & 35.1\end{array}$

Data source: NES (2002).

Notes: Based on seven-point scale (1-7) on ideology and party identification. Extreme position refers to the leftmost (1) and rightmost point (7) for 'Left' and 'Right' on this scale, respectively, whereas clear position refers to points 1 and 2 for 'Left' and 6 and 7 for 'Right' on this scale.

This paper examines the positive and normative implications of parties' motive to cater to their core constituencies for the direction and timing of policy reforms. In particular, we are interested in understanding the role of ideological polarization, which we measure by the share of diehard constituencies of parties in their potential number of voters. Prima facie, a rise in ideological polarization seems to bring about more policy divergence and therefore appears to stand in conflict with social welfare

\footnotetext{
${ }^{3}$ Tab. 1 draws on the standard source for survey evidence in the political science literature, the American National Election Study (NES, 2002). Respondents answered the following question: "We hear a lot of talk these days about liberals and conservatives. When it comes to politics, do you usually think of yourself as Extremely Liberal, Liberal, Slightly Liberal, Moderate or Middle of the Road, Slightly Conservative, Conservative, Extremely Conservative, or haven't you thought much about this?" (NES, 2002; question F1).
} 
maximization-driven policy reforms. Indeed, the previous literature on polarization and policy choice suggests that polarization is unambiguously detrimental for welfare. For instance, Alesina (1988) analyzes a model in which parties are driven by both policy outcomes and the desire to win the elections, but cannot commit to their announced policy platforms after being elected to office. This renders any attempt to propose policy platforms other than their "ideal" ones as incredible under a finite time horizon, whereas in an infinitely repeated game credibility may arise from the possibility to build reputation. However, this becomes more difficult with more polarization, as measured by an increase in the distance between the parties' ideal points. In a more recent paper, Schultz (1996) examines the impact of polarization on the efficiency of public goods provision. In a model where parties are better informed than voters about provision costs, and at least one party has preferences regarding public goods provision that differ sufficiently from those of the median voter (i.e., there is sufficient polarization), public goods provision is inefficient.

Contrary to conventional wisdom, we show that a rise in ideological polarization may in general increase welfare. This result is derived by employing a dynamic twoparty political economy framework, in which parties seek to maximize vote share and face the trade-off between catering to their respective diehard constituencies on the one hand and 'middle of the road' voters with no partisan affiliation on the other hand. In contrast to diehards which are driven by ideology, 'middle of the road' voters care about the state of the economy in the sense that a policy reform is desirable for them when the fundamentals of the economy change. However, information is "sticky" in the sense that the process of information diffusion about the state of the economy, which is determined by some exogenous stochastic process, is imperfect. ${ }^{4}$ In such a set up, we show that an increase in ideological polarization may mitigate the friction in information flow, and thereby enhance social welfare.

\footnotetext{
${ }^{4}$ Slow dissemination of information is at the core of recent macroeconomic models of price adjustment as proposed, e.g., by Mankiw and Reis (2002) and Caroll (2003), and may be rationalized by limited channels of humans for absorbing information, as suggested by Sims (2003). For empirical evidence of such "boundedly rational" behavior in various contexts, see Caroll (2003) and Gabaix et al. (2003).
} 
The structure of the remainder of the paper is as follows. In the coming section we present the basic model. In section 3 we characterize the political equilibrium for the 'monopolistic' regime, namely the case where one party optimally responds to a fixed policy platform set by the other party, and examine the normative implications. In section 4 we turn to the 'competitive' case with two active (i.e., strategically interacting) parties. Section 5 briefly discusses some empirical evidence which supports our critical hypotheses on the behavior of diehard voters. Section 6 concludes.

\section{Basic Structure of the Model}

Consider an economy with two political parties, called leftwing $(L)$ and rightwing $(R)$ party. Each period $t=0,1,2, \ldots$ parties simultaneously choose a platform $P^{t}$ from a one-dimensional and time-invariant policy space $\mathcal{P} \in\left[\bar{P}_{L} \bar{P}_{R}\right] \subset \mathbb{R}$, elections take place, and the political outcome is determined by majority rule.

The economy bounces stochastically between states drawn from the time-invariant space $\mathcal{S}=\left\{S_{1}, S_{2}\right\}$ according to a symmetric Markov process. For instance, $S_{1}$ and $S_{2}$ may be thought of the economy's fundamentals which (stochastically) change over time. Let $S^{t}$ denote the state of the economy in period $t$ and let $q=\operatorname{prob}\left\{S^{t+1}=\right.$ $\left.S_{i} \mid S^{t}=S_{i}\right\}$ be the probability that the economy is in state $S_{i}$ at date $t+1$ given that it was in state $S_{i}$ in $t, i=1,2, q \in(0,1)$. Thus, $(1-q)^{-1}$ is the expected number of successive periods in which the economy is in a particular state ("degree of persistence"). For concreteness $S^{0}$ is given by $S_{1}$.

There are three groups of voters, leftwing diehards, rightwing diehards and "middle of the road" $(M)$ individuals. For each group, there is a continuum of individuals, in mass $n_{L}>0, n_{R}>0$ and $n_{M} \equiv 1$, respectively. Diehard voters and $M$-voters differ in their sensitivity of policy preferences with respect to the state of the economy. Voting behavior at each date of a typical $M$-voter, indexed $j$, is determined by maximization

of the present discounted value of the future stream of perceived utility $u\left(P^{t}, \hat{S}^{t, j}\right)$, where $\hat{S}^{t, j} \in\left\{S_{1}, S_{2}\right\}$ denotes the state of the economy at time $t$ as perceived by 
individual $j$. Let $u(P, \cdot)$ be continuous and strictly quasi-concave as function of $P$, and suppose that, for each state of the economy, $P_{i}^{*} \equiv \arg \max _{P \in \mathcal{P}} u\left(P, S_{i}\right)$ is in the interior of the policy space, ${ }^{5}$ i.e. $P_{i}^{*} \in\left(\bar{P}_{L}, \bar{P}_{R}\right), i=1,2$. We assume that $u\left(P^{t}, S_{i}\right)$ is the actual utility derived from $P^{t}$ at date $t$ if $S^{t}=S_{i}, i=1,2$. (This will become relevant for the normative analysis, whereas perceptions of $M$-voters matter for voting behavior.)

There are many policy issues which are consistent with our set up, where some exogenous shift in the fundamentals beyond the control of the policy maker calls for policy reform. For instance, a balanced-budget rule may be an efficient disciplining device for bureaucrats in times of small business cycle swings but is harmful when the economy is prone to energy crises from both a tax-smoothing perspective (as suggested by dynamic optimal taxation theory) and in view of Keynesian stabilization policies (see, e.g., Alesina and Perotti, 1996). In such a case $S$ may refer to oil price volatility, and $P$ could measure the maximum public debt to GDP ratio.

We turn next to introduce the formation of perception by $M$-voters. Following the literature on "sticky" information, based on limitations of humans to absorb information which gives rise to inattention and thus to a slow dissemination of information (e.g., Mankiw and Reis, 2002; Caroll, 2003; Sims, 2003), we make two generic assumptions. First, we assume that not all $M$-voters immediately adjust their perception about the state of the economy to the true one when it changes. Second, the longer the economy persists in a given state, the higher is the fraction of population that perceives it correctly. To capture these patterns we focus on the following formulation. Let $x_{i}^{t}$ denote the fraction of $M$-voters in period $t$ who believe that the economy currently is in state $S_{i}, i=1,2$, i.e., $x_{1}^{t}+x_{2}^{t}=1$. (Formally, $x_{i}^{t}$ is the measure of the set $\left\{j \mid \hat{S}^{t, j}=S_{i}\right\}, i=1,2$.) We assume that $x_{i}^{t}$ evolves according to the following simple process

$$
x_{i}^{t+1}=\left\{\begin{aligned}
\min \left(x_{i}^{t}+\frac{1}{K}, 1\right) & \text { if } S^{t+1}=S_{i}, \\
\max \left(0, x_{i}^{t}-\frac{1}{K}\right) & \text { if } S^{t+1}=S_{i^{\prime}},
\end{aligned}\right.
$$

$i \neq i^{\prime}$, where $K \geq 1$ is an integer and, for concreteness, $x_{1}^{0}$ is given as 1 . Note that

\footnotetext{
${ }^{5}$ Note that $P_{1}^{*}$ and $P_{2}^{*}$ are unique by virtue of our assumptions on $u$.
} 
the parameter $K$ measures the degree of information stickiness, i.e., the larger $K$ is, the slower the diffusion of information. ${ }^{6}$ For future reference denote by $z^{t}$ the tuple $\left(S^{t}, x_{1}^{t}\right)$.

Diehard voters are characterized as follows. Leftwing diehards never vote for party $R$ and rightwing diehards never support party $L$. The preferred policy of leftwing diehards is $\bar{P}_{L}$, whereas the one of rightwing diehards is $\bar{P}_{R} . \bar{P}_{L}$ and $\bar{P}_{R}$ are common knowledge. Within the two groups of diehard voters, individuals are heterogenous in the utility $\gamma$ derived from voting for (i.e., supporting) their respective party. Let $F_{L}(\gamma)$ and $F_{R}(\gamma)$ denote the c.d.f. of $\gamma$ for leftwing and rightwing diehards, respectively, and $f_{L}(\gamma)$ and $f_{R}(\gamma)$ the respective p.d.f. For $y=L, R$, both $F_{y}(\gamma)$ and $f_{y}(\gamma)$ are assumed to be continuous, with support being the interval $[0, \bar{\gamma}]$. If proposed platform $P_{L}^{t}$ of party $L$ at time $t$ differs from $\bar{P}_{L}$, a leftwing diehard obtains disutility $P_{L}^{t}-\bar{P}_{L}$, i.e., she supports party $L$ if $\gamma \geq P_{L}^{t}-\bar{P}_{L}$. Otherwise, she withdraws support and abstains from voting (not turning to party $R$ either) and derives zero utility. ${ }^{7}$ Thus, given platform $P_{L}^{t}$, the mass of leftwing diehards supporting party $L$ is given by $\left[1-F_{L}\left(P_{L}^{t}-\bar{P}_{L}\right)\right] n_{L}$. Similarly, suppose that given platform $P_{R}^{t}$, the mass of rightwing diehards supporting party $R$ is given by $\left[1-F_{R}\left(\bar{P}_{R}-P_{R}^{t}\right)\right] n_{R}$. Let us suppose $\bar{\gamma} \geq \bar{P}_{R}-\bar{P}_{L}$. This ensures that party $L$ still has diehard voters even when setting a platform close to $\bar{P}_{R}{ }^{8}$

\footnotetext{
${ }^{6}$ Information diffusion about the state of the economy may be modelled in alternative ways. For instance, in a similar way to Mankiw and Reis (2002) and Carroll (2003) who model inflation expectations, we could assume that each period a fraction $\lambda$ of $M$-individuals learn the current state, whereas all other individuals retain the view held in the previous period. As a result, information dissipates as follows: $x_{i}^{t+1}=x_{i}^{t}+\lambda\left(1-x_{i}^{t}\right)$ if $S^{t+1}=S_{i}$ and $x_{i}^{t+1}=(1-\lambda) x_{i}^{t}$ if $S^{t+1}=S_{i^{\prime}}$, $i \neq i^{\prime}$. An alternative way to think about this is as follows. Suppose a fraction $\lambda$ of $M$-individuals are 'experts', who immediately grasp the economic situation correctly, and update their perception accordingly (for instance, due to higher intellectual capacity, better exposure to information, more interest in politics, and the like). After learning a new state, $M$-individuals randomly match with each other every period, such that non-experts learn the current state when meeting an expert. Similarly, process (1) is implied by assuming that there are $1 / K$ experts each meeting exactly one non-expert who holds wrong beliefs (if there are such individuals) each period. It is easy to see that, assuming $\lambda=1 / K$, this leads to faster dissemination of information than the former process with random matching. Although both kinds of "herding" behavior are similar in spirit, assuming the former process rather than the one in (1) complicates our analysis, however, to the point of analytical intractability.

${ }^{7}$ In contrast, for simplicity, abstention of $M$-voters is exogenous, i.e., there is a unit mass of $M$-individuals in the electorate.

${ }^{8}$ Section 5 discusses empirical evidence which supports our assumptions on the behavior of diehard voters, showing that (i) ideology strongly affects partisanship, (ii) partisanship provides social identi-
} 
We turn next to the political parties. The utility derived by party $y=L, R$ in period $t$ is assumed to be an increasing function $v_{j}$ of the number of supporters in $t$, denoted $N_{j}^{t}$. The objective function of party $y=L, R$ in period $t$ reads $\sum_{s=t}^{\infty}\left(\rho_{y}\right)^{s} v_{y}\left(N_{y}^{s}\right)$, $0<\rho_{y}<1$, i.e., parties are completely opportunistic/"Downsian" (Downs, 1957). The reason why parties may be motivated by the number of supporters rather than aiming at a simple majority may be manifold (but exogenous to the model). For instance, the seats in parliament may depend on vote share, and accordingly, a larger number of parliament members affiliated with the party may be eligible for certain 'perks' or privileges. Moreover, decisions in parliament may require supermajority. ${ }^{9}$

Given the objective functions of parties, this implies that in each period $t$ party $y=L, R$ simply maximizes the number of supporters $N_{y}^{t}$. Denote by $m_{y}^{t}$ the number of $M$-voters which support party $y$ at time $t$. Thus, $N_{L}^{t}$ and $N_{R}^{t}$ are given by

$$
N_{L}^{t}=\left[1-F_{L}\left(P_{L}^{t}-\bar{P}_{L}\right)\right] n_{L}+m_{L}^{t}
$$

and

$$
N_{R}^{t}=\left[1-F_{R}\left(\bar{P}_{R}-P_{R}^{t}\right)\right] n_{R}+m_{R}^{t}
$$

respectively. Note that one can interpret the objective functions along the lines of the standard literature in political economy in which parties are usually assumed to be driven by both ideology and power hunger (see e.g. Dixit and Londregan, 1998; Drazen, 2000; Persson and Tabellini, 2000). ${ }^{10}$ In a sense we provide a microfoundation to the somewhat vague ideology-term in the objective of parties by describing the trade-off faced by parties as one between their ideology-driven partisans ("diehards") and voters who adapt their policy preferences to changing economic environments.

fication which makes defection psychologically difficult, and (iii) voting abstention is strongly related to the preferred party's proposed policy platforms.

${ }^{9}$ See Dixit and Londregan (1998, p. 506f.) for further discussion of the assumption that parties are motivated by their vote share.

${ }^{10}$ To see this note that the first term in the objective function defines the loss associated with deviating from the ideal point given by $\bar{P}_{L}$ and $\bar{P}_{R}$ for party $L$ and $R$, respectively. Then one can refer to $M$-voters as the entire electorate and interpret $n_{y}$ accordingly as the relative importance of ideology vis a vis power per se for party $y=L, R$. (The latter Downsian motive is called 'egorance' by Rogoff and Sibert, 1988.) 
In the sense that an increase in $n_{L}$ or $n_{R}$, respectively, induces parties to put more weight on their diehard constituencies, it seems natural to provide the following simple measure for ideological polarization. Society A is said to be more polarized than society B if $n_{y}^{A} /\left(n_{M}^{A}+n_{y}^{A}\right) \geq n_{y}^{B} /\left(n_{M}^{B}+n_{y}^{B}\right)$ for $y=L, R$, with at least one strict inequality. In words, the share of the diehard constituency of party $y$ in its potential number of voters (which does not include the diehards of the other party) in society A strictly exceeds that of society B for at least one of the parties, and weakly exceeds it for both parties. ${ }^{11}$

We assume that parties observe $x_{i}^{t}, i=1,2$, (the perception distribution of $M$-voters) but may or may not observe the true state of the economy. Note that as parties' objectives do not depend on the true state and $M$-voters are aware of this fact, no signaling will take place, and an information asymmetry with respect to $S^{t}$ will have no implication on the perception of voters. ${ }^{12}$

We will look for a subgame-perfect Nash equilibrium in the continuation game. One simplifying assumption we implicitly made is that the platforms set by political parties do not affect the state variable $z^{t}=\left(S^{t}, x_{1}^{t}\right)$. This implies that restricting attention to the Nash equilibrium period by period, provided that all parties base their strategies on the current information as specified above, forms a Markov perfect equilibrium for the continuation game. Also note that a typical $M$-voter $j$ chooses $P^{t} \in\left\{P_{L}^{t}, P_{R}^{t}\right\}$ to maximize perceived utility $u\left(P^{t}, \hat{S}^{t, j}\right)$ at date $t$.

\section{One Active Party ("Monopoly")}

We start by analyzing a simple case in which party $R$ is purely ideologically driven, thus seeking to maximize the support within its diehard constituency, thereby setting

\footnotetext{
${ }^{11}$ Since an increase in polarization means that population weights shift from the center to the sides of the policy space, our measure of polarization is an application of the axiomatically derived measure (applicable for various contexts) by Esteban and Ray (1994).

${ }^{12}$ In contrast, Schultz (1996) and Cukierman and Tommasi (1998a, 1998b) present models in which the state of the economy is known to parties but not to voters, and enters the parties' objectives. In such a set up, voters' perception may be affected by policy platforms in equilibrium.
} 
its platform to $\bar{P}_{R}$ in all periods. ${ }^{13}$ For instance, we may assume that $M$-voters believe that party $R$ is only concerned about ideology and thus in case it is elected will resort to its diehard constituency. Then no matter what party $R$ proposes it will be discounted by the $M$-voters. That said, the optimal response to party $R$ will be indeed to fulfil this prophecy.

Suppose for simplicity that if $M$-voters are indifferent between the platforms set by the two parties, they support party $L .{ }^{14}$ Also for simplicity, we assume that if party $L$ is indifferent between two platforms, it chooses the platform which is closer to $\bar{P}_{L}$. Let us define

$$
P_{i}^{\min }(P) \equiv \min \left(P^{\prime} \in \mathcal{P} \mid u\left(P^{\prime}, S_{i}\right) \geq u\left(P, S_{i}\right)\right), i=1,2,
$$

where we suppose $P_{1}^{\min }\left(\bar{P}_{R}\right) \neq P_{2}^{\min }\left(\bar{P}_{R}\right)$; without loss of generality, let

$$
P_{1}^{\min }\left(\bar{P}_{R}\right)>P_{2}^{\min }\left(\bar{P}_{R}\right)\left[\geq \bar{P}_{L}\right]
$$

\subsection{Behavior of Party $L$}

As we can restrict attention to period by period outcomes, we suppress the time index $t$ in the following wherever it does not lead to confusion. Given $P_{R}=\bar{P}_{R}$, our assumptions imply the following for the payoff function of party $L$.

Lemma 1. Under A1,

$N_{L}=\pi_{L}\left(P_{L}, \bar{P}_{R}\right) \equiv\left\{\begin{array}{c}{\left[1-F_{L}\left(P_{L}-\bar{P}_{L}\right)\right] n_{L} \text { if } P_{L} \in\left[\bar{P}_{L}, P_{2}^{\min }\left(\bar{P}_{R}\right)\right)} \\ {\left[1-F_{L}\left(P_{L}-\bar{P}_{L}\right)\right] n_{L}+1-x_{1} \text { if } P_{L} \in\left[P_{2}^{\min }\left(\bar{P}_{R}\right), P_{1}^{\min }\left(\bar{P}_{R}\right)\right)} \\ {\left[1-F_{L}\left(P_{L}-\bar{P}_{L}\right)\right] n_{L}+1 \text { if } P_{L} \in\left[P_{1}^{\min }\left(\bar{P}_{R}\right), \bar{P}_{R}\right] .}\end{array}\right.$

\footnotetext{
${ }^{13}$ A similar implication is derived by Cukierman and Tommasi (1998a), who assume a higher level of commitment of an incumbent to the voters (to implement its proposed policy) relative to a challenger.

${ }^{14}$ Alternatively, one may assume that votes are split equally by $M$-individuals in case of a tie (as we do in section 4, where both parties are active). This would not alter the basic insights from the analysis in this section but would be costly in terms of expositional simplicity.
} 
Proof. Consider the first line in (5). By virtue of assumption A1 and the definition in (4), it follows from the single-peakedness of $u$ that only leftwing diehards support party $L$. Moreover, recall that $M$-voters support $L$ whenever they are indifferent between two parties. Thus, if $P_{L} \geq P_{2}^{\min }\left(\bar{P}_{R}\right)$, party $L$ receives support from a mass $x_{2}=1-x_{1}$ of $M$-voters who believe the economy is in state 2 . If $P_{L} \geq P_{1}^{\min }\left(\bar{P}_{R}\right)$, also the remaining $M$-individuals support party $L$. This concludes the proof.

Let $\hat{P}_{L} \equiv \arg \max _{P_{L} \in \mathcal{P}} \pi_{L}\left(P_{L}, \bar{P}_{R}\right)$ denote the optimal response of party $L$ to $\bar{P}_{R}$. Our first proposition characterizes the optimal choice of party $L$. The proof of this proposition, as those of all other formal subsequent statements, are relegated to Appendix A.

Proposition 1. Under A1. Suppose $F_{L}\left(P_{1}^{\min }\left(\bar{P}_{R}\right)-\bar{P}_{L}\right) n_{L}<1,{ }^{15}$ and let

$$
c\left(\bar{P}_{R}, \bar{P}_{L}, n_{L}\right) \equiv\left[F_{L}\left(P_{1}^{\min }\left(\bar{P}_{R}\right)-\bar{P}_{L}\right)-F_{L}\left(P_{2}^{\min }\left(\bar{P}_{R}\right)-\bar{P}_{L}\right)\right] n_{L} .
$$

Then (i) $x_{1} \leq c\left(\bar{P}_{R}, \bar{P}_{L}, n_{L}\right)$ implies $\hat{P}_{L}=P_{2}^{\min }\left(\bar{P}_{R}\right)$, whereas (ii) $x_{1}>c\left(\bar{P}_{R}, \bar{P}_{L}, n_{L}\right)$ implies $\hat{P}_{L}=P_{1}^{\min }\left(\bar{P}_{R}\right)$.

The dilemma faced by the policy maker is to choose between $P_{1}^{\min }\left(\bar{P}_{R}\right)$, attracting all $M$-voters, and $P_{2}^{\min }\left(\bar{P}_{R}\right)$, attracting more diehards but only $M$-voters who believe that the state of the economy is $S_{2}$. According to Proposition 1, in this case, $P_{1}^{\min }\left(\bar{P}_{R}\right)$ is chosen whenever the share of $M$-voters who currently believe that the state of the economy is $S_{1}, x_{1}$, is sufficiently high, and $P_{2}^{\min }\left(\bar{P}_{R}\right)$ is chosen otherwise. The threshold $c\left(\bar{P}_{R}, \bar{P}_{L}, n_{L}\right)$ reflects the loss of diehard voters when party $L$ switches policy from $P_{2}^{\min }\left(\bar{P}_{R}\right)$ to $P_{1}^{\min }\left(\bar{P}_{R}\right)$, where it gains (a mass of) $c$ diehards from the opposite switch. Similarly, $x_{1}$ is the gain in $M$-voters when switching from $P_{2}^{\min }\left(\bar{P}_{R}\right)$ to $P_{1}^{\min }\left(\bar{P}_{R}\right)$, and the loss when switching in the opposite direction. Note that assumption A1 implies

\footnotetext{
${ }^{15}$ Otherwise, $n_{L}>1=n_{M}$ necessarily holds, which implausibly implies that the population of diehards exceeds that of the $M$-voters. Suggestive evidence, supporting this implausibility, may be found in Tab. 1, interpreting voters possessing extreme party identification as diehards. (We analyze the cases arising when presumption $F_{L}\left(P_{1}^{\min }\left(\bar{P}_{R}\right)-\bar{P}_{L}\right) n_{L}<1$ does not hold in a supplement available on request.)
} 
$c>0$ and $F_{L}\left(P_{1}^{\min }\left(\bar{P}_{R}\right)-\bar{P}_{L}\right) n_{L}<1$ implies $c<1$. Suppose now the state of the economy is $S_{2}$, say, and the current policy chosen is $P_{2}^{\min }\left(\bar{P}_{R}\right)$. Also suppose the state of the economy changes and persists for a while. To exemplify the role of the switching cost and the stickiness of information consider two scenarios. One scenario is where $K=1$ (i.e., perfect information of $M$-voters), then $x_{1}=1$ if $S=S_{1}$ and $x_{1}=0$ otherwise. Thus, party $L$ immediately switches to $P_{1}^{\min }\left(\bar{P}_{R}\right)$ when the state of the economy changes from $S_{2}$ to $S_{1}$. In contrast, if $K>1$, party $L$ does not adjust its policy immediately. In fact, the larger $c$ (the switching cost) is, the longer it would take to change the policy. An implication is that when information is sticky, and the core constituency of party $L, n_{L}$, is relatively large, then party $L$ would be slow in implementing reforms that require a rightward shift from $P_{2}^{\min }\left(\bar{P}_{R}\right)$ to $P_{1}^{\min }\left(\bar{P}_{R}\right)$. By a similar line of reasoning, party $L$ would be quick to adopt reforms in the opposite direction. ${ }^{16}$ To conclude, higher ideological polarization does not necessarily delay reforms in a positive sense.

\subsection{Normative Implications}

Next, we turn to normative implications of the behavior of party $L$. To avoid trivial cases, we assume that party $L$ always wins the elections. A sufficient condition for that would be to assume that the diehard population of party $R, n_{R}$, is relatively small. Throughout the paper, social welfare will be measured by the discounted expected utility derived by a fully informed $M$-voter, that is, the utility based on the true state of the economy. Two remarks are in order. First, note that expected utility relates to the stochastic process that determines the state of the economy and not to the fact that there is a distribution of perceptions. We will assume that the discount rate is sufficiently small, hence, we confine attention to the stationary welfare flow (i.e., the average utility based on the limiting distribution of the state variable $z=\left(S, x_{1}\right)$, which we characterize below in Lemma 2). Moreover, note that we

\footnotetext{
${ }^{16}$ For instance, conservative governments may be quick to implement measures for internal security (which may be costly in terms of resources and civil liberties) in times of high terror threats, but may be slow to switch back to a liberal environment after terror groups dissolve.
} 
focus on the welfare of the $M$-voters only, which can be warranted in two manners. First, following the possible interpretation of the diehard population as the ideology component in a standard objective function of parties, accounting for both power hunger and ideological motives, $M$-voters form the entire electorate. Second, even when the welfare of diehards does matter, one can assume that the gain derived by one party's diehard constituency associated with policy reforms is just outweighed by the loss suffered by the other party's diehards, where gain and loss is measured in deviations from core ideology.

We are interested in examining how the presence of the friction in information flow (i.e., $K>1$ ) and the existence of switching costs $(c)$ affect utility of $M$-voters. Define $u_{i^{\prime}, i} \equiv u\left(P_{i^{\prime}}^{\min }\left(\bar{P}_{R}\right), S_{i}\right), i^{\prime}, i=1,2$. Recalling that the utility function of $M$-voters has an interior maximum in both states of the economy, by virtue of assumption A1 and the definition of $P_{1}^{\min }\left(\bar{P}_{R}\right)$, it necessarily follows that $u_{2,1}<u_{1,1}$. We illustrate this in panel (a) of Fig. 1 (where $P_{2}^{\min }\left(\bar{P}_{R}\right)=\bar{P}_{L}$ ). However, as regards to $S_{2}$, as illustrated in panel (b) of Fig. 1, there are two possibilities to consider. The first case depicted by the solid line refers to a scenario in which $u_{2,2}>u_{1,2}$, i.e., there would be a welfare gain from switching whenever the state of the economy shifts. This coincides with the natural notion of desirable policy reforms and, in this sense, turns out to be analogous to the case of strategically interacting parties, as analyzed in section 4. By contrast, the second case (without any analogy in section 4) depicted by the dashed line refers to a scenario in which $u_{2,2}<u_{1,2}$. In such a case, welfare is always higher if $P_{1}^{\min }\left(\bar{P}_{R}\right)$ is implemented than under $P_{2}^{\min }\left(\bar{P}_{R}\right)$.

The stochastic process that determines the evolution of $z=\left(S, x_{1}\right)$, given by the Markov process governing the state of the economy and process (1) governing $x_{1}$, is essentially a random walk process with two absorbing states (the cases in which the whole population perceives the state of the economy (correctly) as either $S_{1}$ or as $S_{2}$ ). One can derive the transition matrix for the process, defined over the state set $\mathcal{Z} \equiv \mathcal{S} \times\{0,1 / K, 2 / K, \ldots, 1\}$, and calculate the corresponding limiting distribution. 

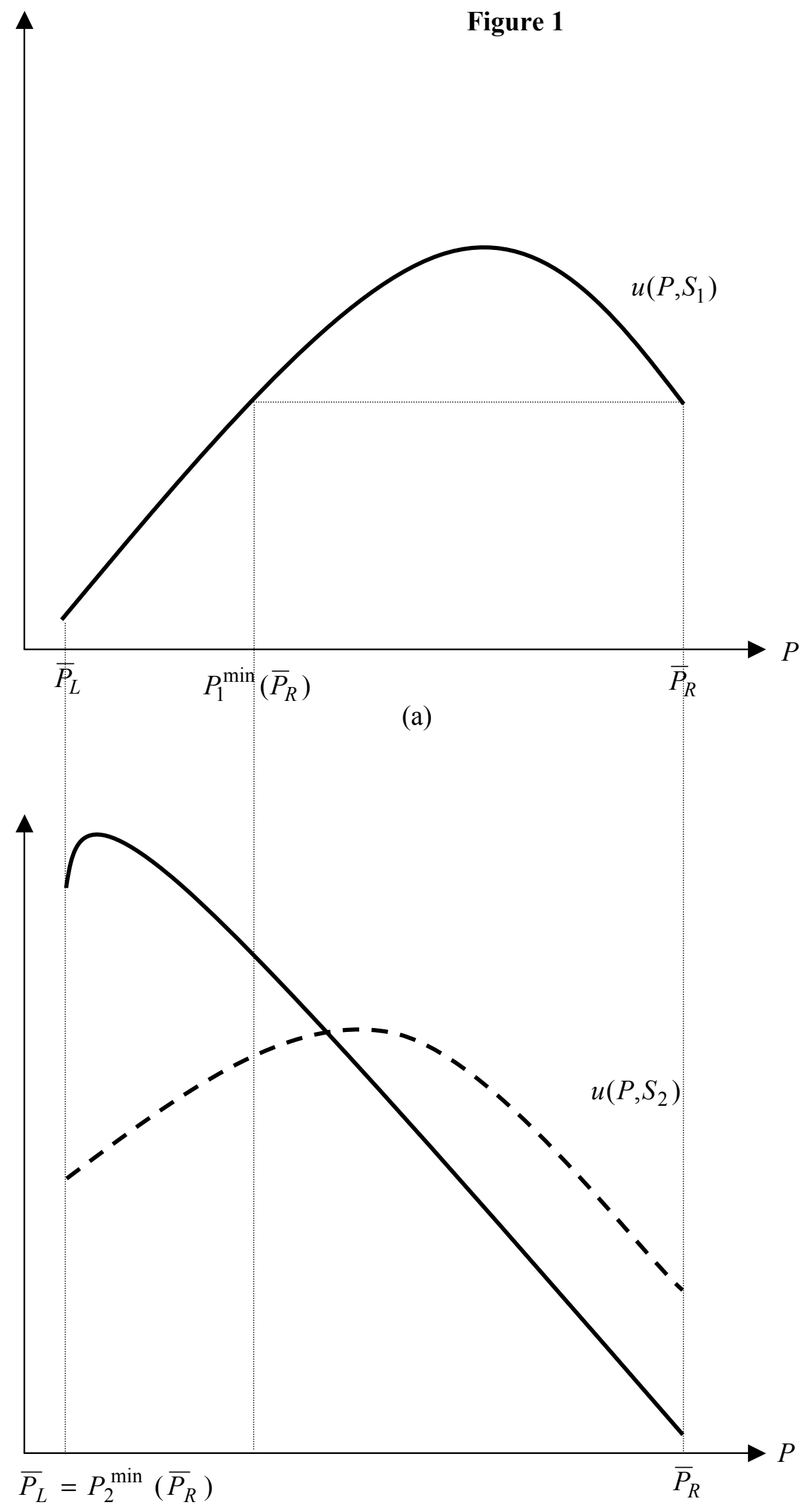

(b) 
The result is stated as Lemma $2 .{ }^{17}$

Lemma 2. As $t \rightarrow \infty$, the distribution of $z^{t}=\left(S^{t}, x_{1}^{t}\right)$ can be characterized as:

$$
\begin{aligned}
& \operatorname{prob}\left\{z^{t}=\left(S_{1}, 1\right)\right\}=\operatorname{prob}\left\{z^{t}=\left(S_{2}, 0\right)\right\}=\frac{0.5}{1+(K-1)(1-q)} \equiv \hat{p}, \\
& \operatorname{prob}\left\{z^{t}=\left(S_{i}, k / K\right)\right\}=(1-q) \hat{p} \text { for all } i=1,2, k=1, \ldots, K-1 .
\end{aligned}
$$

As in each period of time the state of the economy is either $S_{1}$ or $S_{2}$, and the implemented policy is either $P_{1}^{\min }\left(\bar{P}_{R}\right)$ or $P_{2}^{\min }\left(\bar{P}_{R}\right)$, it suffices from a normative perspective to partition the state set $\mathcal{Z}$ into a set of policy relevant subsets given by $\mathcal{Z}_{i^{\prime}, i}, i^{\prime}, i=1,2$, where $\mathcal{Z}_{i^{\prime}, i}$ is defined as the set of all elements of $\mathcal{Z}$ for which the implemented policy is $P_{i^{\prime}}^{\min }\left(\bar{P}_{R}\right)$ and the state of the economy is $S_{i}$. Each subset $\mathcal{Z}_{i^{\prime}, i}$ defines an event with an associated probability measure denoted by $\alpha_{i^{\prime}, i}$. Thus, expected utility, denoted by $E(u)$, is given by $E(u)=\sum_{i^{\prime}} \sum_{i} \alpha_{i^{\prime}, i} \cdot u_{i^{\prime}, i}$. By virtue of the symmetry of the Markov process, it follows that $\sum_{i^{\prime}} \alpha_{i^{\prime}, i}=0.5$ for $i=1,2$. Thus, the expected utility $E(u)$ can be written

$$
E(u)=\alpha_{2,1} \Delta_{2,1}+\alpha_{1,2} \Delta_{1,2}+\beta
$$

where $\Delta_{2,1} \equiv u_{2,1}-u_{1,1}, \Delta_{1,2} \equiv u_{1,2}-u_{2,2}$ and $\beta=0.5\left(u_{1,1}+u_{2,2}\right)$. (Recall that $u_{2,1}<u_{1,1}$, i.e., $\Delta_{2,1}<0$.) In the case where $\Delta_{1,2}<0$ (solid line in panel (b) of Fig. 1) one could refer to $\mathcal{Z}_{1,2}$ and $\mathcal{Z}_{2,1}$ as "mismatch" events in the sense that relative to the set of possible political outcomes, $\left\{P_{1}^{\min }\left(\bar{P}_{R}\right), P_{2}^{\min }\left(\bar{P}_{R}\right)\right\}$, given the state of the economy, the choice taken is suboptimal. In the case where $\Delta_{1,2}>0$, the mismatch events are $\mathcal{Z}_{2,1}$ and $\mathcal{Z}_{2,2}$ since $P_{1}^{\min }\left(\bar{P}_{R}\right)$ is preferred to $P_{2}^{\min }\left(\bar{P}_{R}\right)$ by $M$-voters in either

\footnotetext{
${ }^{17}$ From Lemma 2, one can define a positive measure of policy reform stickiness, namely the mean time it takes to switch between policies. This measure is formally derived for the monopoly case in Appendix B (and could be applied mutatis mutandis to the competitive case in section 4). However, as we show in the following, a higher mean time between switches is not necessarily detrimental. Thus, one cannot judge by this positive measure of stickiness alone the normative implications.
} 
state of the economy. ${ }^{18}$ Proposition 2 states formally the normative implications of the political equilibrium, where we take the stationary flow of expected utility $E(u)$ as our welfare measure. (An informal interpretation would follow.)

Proposition 2. Suppose $F_{L}\left(P_{1}^{\min }\left(\bar{P}_{R}\right)-\bar{P}_{L}\right) n_{L}<1$ and assumption A1 holds.

(a) If $\Delta_{1,2}<0$, then (i) when the degree of information stickiness is small ( $K$ is sufficiently small), $E(u)$ is strictly decreasing in $K$, (ii) when information is sticky $(K>1)$, then an increase in $n_{L}$ (higher polarization) may result in an increase in $E(u)$, and (iii) $E(u)$ is strictly increasing in $q$.

(b) If $\Delta_{1,2}>0$, then (i) for any $K$, an increase in $K$ may result in an increase in $E(u)$, (ii) if anything, $E(u)$ is decreasing in $n_{L}$, and (iii) the impact of an increase in $q$ on $E(u)$ is ambiguous.

Let us start with the discussion of part (a). First, as long as $K$ is not too large (the degree of information stickiness is limited), a rise in $K$ reduces welfare, $E(u){ }^{19}$ In particular, part (a) of Proposition 2 implies that $E(u)$ is higher under perfect information $(K=1)$ than in the case of imperfect information $(K>1)$. This is because under perfect information the policy chosen by party $L$ is always optimal relative to the set of possible political outcomes, $\left\{P_{1}^{\min }\left(\bar{P}_{R}\right), P_{2}^{\min }\left(\bar{P}_{R}\right)\right\}$, i.e., there

\footnotetext{
${ }^{18}$ Also note that due to "imperfect competition" among parties, even with perfect information (i.e., if $K=1)$, the choice in any event is suboptimal compared to the first-best social optimum $\left(P_{i}^{*}\right.$ for $\left.S_{i}, i=1,2\right)$.

${ }^{19}$ If $\Delta_{2,1} \neq \Delta_{1,2}$, then an increase in $K$ may increase $E(u)$ when $K$ is large. This is because a higher $K$ may have a non-uniform impact on mismatch probabilities $\alpha_{1,2}$ and $\alpha_{2,1}$. That is, although $\alpha_{1,2}+\alpha_{2,1}=\frac{0.5(K-1)(1-q)}{1+(K-1)(1-q)}$ (see the proof of Proposition 2 in Appendix A) unambiguously rises with $K$, it is possible that, say, $\alpha_{2,1}$ decreases with $K$. Thus, if at the same time $\left|\Delta_{2,1}\right|>>\left|\Delta_{1,2}\right|$, i.e., the welfare loss from policy $P_{2}^{\min }\left(\bar{P}_{R}\right)$ when the state of the economy is $S_{1}$ is sufficiently higher than the loss from policy $P_{1}^{\min }\left(\bar{P}_{R}\right)$ when the state of the economy is $S_{2}$, then $E(u)$ rises with $K$. When $K$ is not too large, however, the effect of the rise in the overall probability of mismatch turns out to be dominating the other effect of a shift in probabilities across mismatch events. Anyway, we do not consider the possibility that $E(u)$ rises with $K$ to be interesting in the case $\Delta_{1,2}<0$, as it seems to be a knife-edge scenario. Basically, it is merely an implication of the fact that the stochastic variable $x_{1}$ evolves in discrete steps, i.e., $x_{1} \in\{0,1 / K, 2 / K, \ldots, 1\}$. Moreover, note that if $\Delta_{2,1}=\Delta_{1,2}$, then the shift in probability across the two mismatch events has no impact on welfare, as can be observed from (8). In this case, the result holds for any $K$. In fact, the shift in probabilities across mismatch event can work in the other direction by further increasing the likelihood of the more harmful mismatch event (among the two possible).
} 
is zero probability of a mismatch event $\left(\alpha_{2,1}=\alpha_{1,2}=0\right.$ if $\left.K=1\right)$. In contrast, if $K>1$, then it is possible that party $L$ chooses, say, $P_{2}^{\min }\left(\bar{P}_{R}\right)$ (which happens if $x_{1} \leq c$, according to Proposition 1), although the state of the economy is $S_{1}$, or chooses $P_{1}^{\min }\left(\bar{P}_{R}\right)$ although the economy is in $S_{2}$. Second, if $n_{L}$ and thus switching costs $c$ increase (i.e., ideological polarization rises), if anything, the probability of a mismatch event $\mathcal{Z}_{2,1}$ (i.e., party $L$ chooses $P_{2}^{\min }\left(\bar{P}_{R}\right)$ although the state of the economy is $\left.S_{1}\right), \alpha_{2,1}$, rises and $\alpha_{1,2}$ falls. If the loss in expected utility from an increase in $\alpha_{2,1}$ is lower than the welfare gain from a reduction in $\alpha_{1,2}$, welfare rises. Third, note that whenever $M$-voters have reached consensus regarding the state of the economy (i.e., $\left.z^{t} \in\left\{\left(S_{1}, 1\right),\left(S_{2}, 0\right)\right\}\right)$, there is no mismatch. From (6), as $t \rightarrow \infty$, the probability that the economy is in such an absorbing state, $\hat{p}$, is rising in the degree of persistence of the economy, $(1-q)^{-1}$. Thus, welfare rises if $q$ rises.

Now consider part (b), which refers to the case in which $M$-voters always prefer $P_{1}^{\min }\left(\bar{P}_{R}\right)$ to $P_{2}^{\min }\left(\bar{P}_{R}\right)$. First, expected utility may generally rise if the degree of information stickiness rises. In particular, and in contrast to part (a), welfare may be lower in perfect information than under imperfect information. This is because, when $P_{1}^{\min }\left(\bar{P}_{R}\right)$ is preferred to $P_{2}^{\min }\left(\bar{P}_{R}\right)$ in both states of the economy, a higher $K$ may increase the probability that $P_{1}^{\min }\left(\bar{P}_{R}\right)$ is chosen in $S_{2}, \alpha_{1,2}$. If the gain from this exceeds the welfare loss from an increase in $\alpha_{2,1}$, overall welfare rises. This result is a typical second-best argument, where adding another distortion (i.e., an information friction) to the imperfect competition among parties may raise welfare. Second, since the frequency of party $L$ choosing $P_{1}^{\min }\left(\bar{P}_{R}\right)$ declines with $c$, if anything, higher ideological polarization is detrimental for welfare. Finally, since an increase in the probability that $P_{2}^{\min }\left(\bar{P}_{R}\right)$ is chosen in $S_{1}$ is harmful whereas increase in the probability that $P_{1}^{\min }\left(\bar{P}_{R}\right)$ is chosen in $S_{2}$ is beneficial if $\Delta_{1,2}>0$, welfare may be decreasing or increasing in $q$. 


\section{Two Active Parties ("Competition")}

In the analysis of two competing parties, suppose that if $M$-voters are indifferent between the platforms set by the two parties, half of the votes from each group of individuals go to either party. Analogously to (4), let us define ${ }^{20}$

$$
P_{i}^{\max }(P) \equiv \max \left(P^{\prime} \in \mathcal{P} \mid u\left(P^{\prime}, S_{i}\right) \geq u\left(P, S_{i}\right)\right), i=1,2 .
$$

\subsection{Equilibrium Analysis}

We now turn to the analysis of the role of information diffusion and the role of the diehard constituencies for the (equilibrium) behavior of two Downsian parties which simultaneously choose policy platforms in each period. Regarding possible Nash equilibria in pure strategies, the following first result holds.

Lemma 3. Strategy pairs other than $P_{y}=\bar{P}_{y}$ for $y=L, R$ or $P_{L}=P_{R} \in$ $\left\{P_{1}^{*}, P_{2}^{*}\right\}$ cannot be Nash equilibria in pure strategies.

According to Lemma 3, there may only exist two types of equilibria: either both parties maximize utility of their diehards or they set platforms at the peak of $M$-individuals' utility function for one of the two states of the economy. Conditions for the equilibrium in which parties are oriented to their diehards in pure strategy Nash equilibrium and their positive implications are considered in a supplement to this paper available on request. The focus, however, lies on the case in which either $P_{1}^{*}$ or $P_{2}^{*}$ may be implemented in equilibrium.

We first continue by considering necessary conditions for a pure strategy equilibrium in which $P_{L}=P_{R} \in\left\{P_{1}^{*}, P_{2}^{*}\right\}$. It is crucial for our analysis to assume that the preferred policy of $M$-voters depends on the state of the economy. Without loss of generality, suppose

$$
\bar{P}_{R}>P_{1}^{*}>P_{2}^{*}>\bar{P}_{L}
$$

\footnotetext{
${ }^{20}$ Note from the single-peakedness of $u$ and (4) that $P_{i}^{\min }(P)=P$ for all $P \leq P_{i}^{*}$ and, similarly, $P_{i}^{\max }(P)=P$ for all $P \geq P_{i}^{*}$, according to $(9), i=1,2$.
} 
Lemma 4. Under A2, in a pure strategy Nash equilibrium such that $P_{L}=P_{R}=$ $P_{i}^{*}, F_{L}\left(P_{i}^{*}-\bar{P}_{L}\right) n_{L} \leq 0.5, F_{R}\left(\bar{P}_{R}-P_{i}^{*}\right) n_{R} \leq 0.5$ and $x_{i}>0.5$ must hold, $i=1,2$.

According to Lemma 4, for a pure strategy equilibrium such that $P_{L}=P_{R}=P_{i}^{*}$ to exist (i.e., policy platforms of parties fully converge), two conditions are necessary. First, diehard voters must not be too important quantitatively (for instance, if $n_{L}, n_{R} \leq 0.5, P_{L}=P_{R}=P_{i}^{*}$ may be a pure strategy equilibrium), i.e., the gain from deviating towards diehards has to be sufficiently low. Second, a strict majority of $M$-voters have to believe that the state of the economy is $S_{i}, i=1,2 .{ }^{21}$ The next result deals with uniqueness of equilibrium.

Lemma 5. Under A2, given $x_{1} \in[0,1]$, any Nash equilibrium in pure strategies is unique.

We now come to the main result in the positive analysis of the competition case.

Proposition 3. Under A2. Suppose $F_{L}\left(P_{1}^{*}-\bar{P}_{L}\right) n_{L} \leq 0.5$ and $F_{R}\left(\bar{P}_{R}-P_{2}^{*}\right) n_{R} \leq$ 0.5. Then the following holds.

(i) If $x_{1} \geq 0.5+\left[F_{L}\left(P_{1}^{*}-\bar{P}_{L}\right)-F_{L}\left(P_{2}^{\min }\left(P_{1}^{*}\right)-\bar{P}_{L}\right)\right] n_{L} \equiv \bar{x}\left(n_{L}, \bar{P}_{L}, P_{1}^{*}\right)$, then there is a unique Nash equilibrium such that $P_{L}=P_{R}=P_{1}^{*}$.

(ii) If $x_{1} \leq 0.5-\left[F_{R}\left(\bar{P}_{R}-P_{2}^{*}\right)-F_{R}\left(\bar{P}_{R}-P_{1}^{\max }\left(P_{2}^{*}\right)\right)\right] n_{R} \equiv \underline{x}\left(n_{R}, \bar{P}_{R}, P_{2}^{*}\right)$, then there is a unique Nash equilibrium such that $P_{L}=P_{R}=P_{2}^{*}$.

(iii) If $x_{1} \in\left(\underline{x}\left(n_{R}, \bar{P}_{R}, P_{2}^{*}\right), \bar{x}\left(n_{L}, \bar{P}_{L}, P_{1}^{*}\right)\right)$, then no Nash equilibrium in pure strategies exists.

Proposition 3 implies that when a sufficient majority of $M$-voters believe in $S_{i}$ as the state of the economy, parties converge to the same policy platform, $P_{i}^{*}$. However, the necessary conditions for such an equilibrium (in pure strategies) to exist are not sufficient. In particular, if $x_{i}>0.5$ but small, $P_{L}=P_{R}=P_{i}^{*}$ may not be an equilibrium, $i=1,2$, even if the presumptions in Lemma 4 hold. The range $(\underline{x}, \bar{x})$ in

\footnotetext{
${ }^{21}$ Of course, even if $P_{L}=P_{R}=P_{i}^{*}$, policy platforms may be set at inefficient levels from the perspective of $M$-individuals, since the actual state of the economy may be $S_{i^{\prime}}, i^{\prime} \neq i$. This is the subject of the normative analysis below.
} 
which, according to part (iii) of Proposition 3, no Nash equilibrium in pure strategies exists will henceforth be referred to as the 'black hole' range. This range widens if ideological polarization rises. To gain insight why such a 'black hole' range arises, consider, for instance, a situation in which both parties propose $P_{1}^{*}$. In such a case, each party will attract one half of the $M$-voters' constituency, which equals 0.5 . Now consider, say, a leftward deviation of party $L$ to some $P_{L}>P_{2}^{\min }\left(P_{1}^{*}\right)$. Obviously, party $L$ will lose all $M$-voters with perception $\hat{S}=S_{1}$ but still attract all $M$-voters with perception $\hat{S}=S_{2}$. Being in a 'black hole' range implies that the number of $M$-voters with perception $\hat{S}=S_{2}$ lies sufficiently close to 0.5 . Thus, the loss of $M$-voters will be rather small. On the other hand, party $L$ will gain the support of additional diehards. Hence, such a deviation will be profitable, rendering an equilibrium $\left(P_{1}^{*}, P_{1}^{*}\right)$ impossible, even if $x_{1}>0.5$. (Also recall that $\left(P_{1}^{*}, P_{1}^{*}\right)$ is the only candidate for a pure strategy equilibrium if $x_{1}>0.5$ under the presumptions of Proposition 3. $)^{22}$

\subsection{An Approximation Result}

In the previous section we have characterized the equilibria of the political game in the two-party case ("competition"). As Proposition 3 states formally, there exists a range of parameters for which no equilibrium in pure strategies exists. Moreover, due to the discontinuity of the parties' payoff functions, also existence of mixed strategy equilibria within the 'black hole' range is not generally ensured. In order to be able to examine the normative implications of the model, we simplify the analysis by assuming that, rather than focusing on the continuum case, the policy set is approximated by a (sufficiently fine) grid. A grid will ensure the existence of equilibrium throughout (including one in mixed strategies in the black hole range), and, provided that it is sufficiently fine, maintain the properties of the continuum case (as stated by Proposition 3). The ability to construct such a grid derives from the discontinuity of the

\footnotetext{
${ }^{22}$ As shown in the supplement to this paper, if $n_{L}$ and $n_{R}$ are not too high (but higher than implied by the presumptions of Proposition 3), for an equilibrium in which $P_{y}=\bar{P}_{y}, y=L, R$ (for at least some $x_{1}$ ) to exist, it is necessary that $x_{1}$ is in a range which includes 0.5 . Interestingly, comparison with Proposition 3 reveals that this is the opposite result as for existence of an equilibrium in which $P_{L}=P_{R}=P_{i}^{*}, i=1,2$.
} 
parties' payoff functions. We turn to state the result formally.

Proposition 4. Under the presumptions of Proposition 3, there exists a sufficiently fine policy grid, given by a subset of the policy space, $\mathcal{P}$, which includes the policy elements $P_{1}^{*}, P_{2}^{*}, \bar{P}_{L}$ and $\bar{P}_{R}$ such that the results stated by Proposition 3 hold; furthermore, there exists a Nash equilibrium in mixed strategies if $x_{1} \in$ $\left(\underline{x}\left(n_{R}, \bar{P}_{R}, P_{2}^{*}\right), \bar{x}\left(n_{L}, \bar{P}_{L}, P_{1}^{*}\right)\right)$.

\subsection{Normative Implications}

We turn next to study the normative implications using the following simple example. We assume that $K=3$ and let the policy grid be comprised of four elements $P_{1}^{*}, P_{2}^{*}, \bar{P}_{L}$ and $\bar{P}_{R}$. We further assume that the distributions of diehard voters satisfy the following properties: $F_{L}\left(P_{2}^{*}-\bar{P}_{L}\right)=F_{R}\left(\bar{P}_{R}-P_{1}^{*}\right)=1 / 2, F_{L}\left(P_{1}^{*}-\bar{P}_{L}\right)=$ $F_{R}\left(\bar{P}_{R}-P_{2}^{*}\right)=3 / 4$, and $F_{L}\left(\bar{P}_{R}-\bar{P}_{L}\right)=F_{R}\left(\bar{P}_{R}-\bar{P}_{L}\right)=1$. We further suppose $4 / 9<n_{y}<2 / 3, y=L, R$, and, last, assume

$$
\begin{aligned}
& u\left(P_{2}^{*}, S_{2}\right)>u\left(P_{1}^{*}, S_{2}\right)=u\left(\bar{P}_{L}, S_{2}\right)>u\left(\bar{P}_{R}, S_{2}\right), \\
& u\left(P_{1}^{*}, S_{1}\right)>u\left(P_{2}^{*}, S_{1}\right)=u\left(\bar{P}_{R}, S_{1}\right)>u\left(\bar{P}_{L}, S_{1}\right) .
\end{aligned}
$$

It follows that $P_{2}^{\min }\left(P_{1}^{*}\right)=\bar{P}_{L}$ and $P_{1}^{\max }\left(P_{2}^{*}\right)=\bar{P}_{R}$. This implies in turn (using the definitions given in Proposition 3) that $\bar{x}=1 / 2+3 n_{L} / 4$ and $\underline{x}=1 / 2-$ $3 n_{R} / 4$. In our simple setting, the state space of the economy is given by $\mathcal{Z}=$ $\left\{\left(S_{1}, 1 / 3\right),\left(S_{1}, 2 / 3\right),\left(S_{1}, 1\right),\left(S_{2}, 0\right),\left(S_{2}, 1 / 3\right),\left(S_{2}, 2 / 3\right)\right\}$. Note that the two absorbing states $\left[\left(S_{1}, 1\right)\right.$ and $\left.\left(S_{2}, 0\right)\right]$, lie outside the 'black hole' range, whereas all other states lie inside. We turn next to verify that in this example indeed the grid is sufficiently fine to satisfy the properties stated in Proposition 3. By virtue of symmetry it suffices to focus on the cases $x_{1}=1$ and $x_{1}=2 / 3$.

We first analyze the case $x_{1}=1$. Following part (i) of Proposition 3, we turn to show that the only Nash equilibrium in pure strategies is the pair $\left(P_{1}^{*}, P_{1}^{*}\right)$. For this purpose we calculate the payoff matrix for the case $x_{1}=1$ in Tab. 2 . 
As a guide to interpreting Tab. 2, consider the case where both parties choose to propose a platform given by $P_{1}^{*}$. In such a case the $M$-voters split evenly between the two parties, as they propose the same platform. Turning next to the diehard constituencies, however, as $P_{1}^{*}$ is relatively more consistent with the core ideology of party $R$, the latter manages to preserve the allegiance of the bulk of its diehard constituency (attracting half of it), whereas party $L$ is left with only the most diehard supporters (which amount to one quarter of its diehard constituency). This can be verified by employing the distribution of diehard voters for the two parties, recalling that $F_{R}\left(\bar{P}_{R}-P_{1}^{*}\right)=1 / 2$ while $F_{L}\left(P_{1}^{*}-\bar{P}_{L}\right)=3 / 4$. Close inspection of the payoff matrix reveals that $\bar{P}_{L}$ and $\bar{P}_{R}$ are dominated strategies for party $R$ and party $L$, respectively, as they are dominated by $\bar{P}_{R}$ and $P_{2}^{*}$, correspondingly. After the first iteration of elimination of strictly dominated strategies, it is easy to verify that $P_{1}^{*}$ is a dominant strategy for party $L$ (employing the fact that $n_{L}<2 / 3$ ). It is also easy to observe that $P_{1}^{*}$ is the best response of party $R$ when $P_{1}^{*}$ is proposed by party $L$. Thus, we conclude that indeed the pair $\left(P_{1}^{*}, P_{1}^{*}\right)$ forms a unique Nash equilibrium in pure strategies for the case $x_{1}=1$, in line with part (i) of Proposition 1. Invoking symmetry, one can show, repeating the above argument, that for the case $x_{1}=0$, the unique Nash equilibrium in pure strategies is given by the pair $\left(P_{2}^{*}, P_{2}^{*}\right)$, which verifies part (ii) of Proposition 3.

We turn next to the case $x_{1}=2 / 3$ (and by virtue of symmetry, $x_{1}=1 / 3$ ), for which we need to show that there exists no Nash equilibrium in pure strategies (thus verifying part (iii) of Proposition 3). By virtue of the finite grid, we will be able to characterize a (unique) Nash equilibrium in mixed strategies for this case. For these purposes we re-calculate the payoff matrix for the case $x_{1}=2 / 3$ in Tab. 3 .

Close inspection of the payoff matrix reveals that $\bar{P}_{L}$ and $\bar{P}_{R}$ are still dominated strategies for party $R$ and party $L$, respectively, as they are (still) dominated by $\bar{P}_{R}$ and $P_{2}^{*}$, correspondingly. Moreover, $P_{2}^{*}$ is dominated by $\bar{P}_{R}$ for party $R$. In the second iteration of elimination of strictly dominated strategies, using the parametric restriction, $4 / 9<n_{L}<2 / 3$, one can show that $P_{2}^{*}$ is dominated by $P_{1}^{*}$ for party $L$. 
Table 2: Payoff matrix for $x_{1}=1$.

\begin{tabular}{|c|c|c|c|c|}
\hline \multicolumn{1}{|c|}{$P_{1}^{*}$} & $P_{2}^{*}$ & $\bar{P}_{R}$ & $\bar{P}_{L}$ \\
\hline$P_{1}^{*}$ & $\frac{n_{L}}{4}+\frac{1}{2}, \frac{n_{R}}{2}+\frac{1}{2}$ & $\frac{n_{L}}{4}+1, \frac{n_{R}}{4}$ & $\frac{n_{L}}{4}+1, n_{R}$ & $\frac{n_{L}}{4}+1,0$ \\
\hline$P_{2}^{*}$ & $\frac{n_{L}}{2}, \frac{n_{R}}{2}+1$ & $\frac{n_{L}}{2}+\frac{1}{2}, \frac{n_{R}}{4}+\frac{1}{2}$ & $\frac{n_{L}}{2}+\frac{1}{2}, n_{R}+\frac{1}{2}$ & $\frac{n_{L}}{2}+1,0$ \\
\hline $\bar{P}_{R}$ & $0, \frac{n_{R}}{2}+1$ & $\frac{1}{2}, \frac{n_{R}}{4}+\frac{1}{2}$ & $\frac{1}{2}, n_{R}+\frac{1}{2}$ & 1,0 \\
\hline $\bar{P}_{L}$ & $n_{L}, \frac{n_{R}}{2}+1$ & $n_{L}, \frac{n_{R}}{4}+1$ & $n_{L}, n_{R}+1$ & $\frac{n_{L}}{2}+\frac{1}{2}, \frac{1}{2}$ \\
\hline
\end{tabular}

Table 3: Payoff matrix for $x_{1}=2 / 3$.

\begin{tabular}{|c|c|c|c|c|}
\hline$L$ & $P_{1}^{*}$ & $P_{2}^{*}$ & $\bar{P}_{R}$ & $\bar{P}_{L}$ \\
\hline$P_{1}^{*}$ & $\frac{n_{L}}{4}+\frac{1}{2}, \frac{n_{R}}{2}+\frac{1}{2}$ & $\frac{n_{L}}{4}+\frac{2}{3}, \frac{n_{R}}{4}+\frac{1}{3}$ & $\frac{n_{L}}{4}+1, n_{R}$ & $\frac{n_{L}}{4}+\frac{5}{6}, \frac{1}{6}$ \\
\hline$P_{2}^{*}$ & $\frac{n_{L}}{2}+\frac{1}{3}, \frac{n_{R}}{2}+\frac{2}{3}$ & $\frac{n_{L}}{2}+\frac{1}{2}, \frac{n_{R}}{4}+\frac{1}{2}$ & $\frac{n_{L}}{2}+\frac{2}{3}, n_{R}+\frac{1}{3}$ & $\frac{n_{L}}{2}+1,0$ \\
\hline $\bar{P}_{R}$ & $0, \frac{n_{R}}{2}+1$ & $\frac{2}{3}, \frac{n_{R}}{4}+\frac{2}{3}$ & $\frac{1}{2}, n_{R}+\frac{1}{2}$ & $\frac{2}{3}, \frac{1}{3}$ \\
\hline $\bar{P}_{L}$ & $n_{L}+\frac{1}{6}, \frac{n_{R}}{2}+\frac{5}{6}$ & $n_{L}, \frac{n_{R}}{4}+1$ & $n_{L}+\frac{1}{3}, n_{R}+\frac{2}{3}$ & $\frac{n_{L}}{2}+\frac{1}{2}, \frac{1}{2}$ \\
\hline
\end{tabular}

Table 4: Payoff matrix for $x_{1}=2 / 3$ without dominated strategies.

\begin{tabular}{|c|c|c|}
\hline \multicolumn{1}{|c|}{$P_{1}^{*}$} & $\bar{P}_{R}$ \\
\hline$P_{1}^{*}$ & $\frac{n_{L}}{4}+\frac{1}{2}, \frac{n_{R}}{2}+\frac{1}{2}$ & $\frac{n_{L}}{4}+1, n_{R}$ \\
\hline $\bar{P}_{L}$ & $n_{L}+\frac{1}{6}, \frac{n_{R}}{2}+\frac{5}{6}$ & $n_{L}+\frac{1}{3}, n_{R}+\frac{2}{3}$ \\
\hline
\end{tabular}


Thus, we are left with the two-by-two payoff matrix in Tab. 4.

Let $0<l<1$ and $0<r<1$ denote the probability measures assigned by party $L$ and party $R$, respectively, to the platform $P_{1}^{*}$ for $x_{1}=2 / 3$, and, by symmetry, to $P_{2}^{*}$ for $x_{1}=1 / 3$. We obtain reaction functions for $x_{1}=2 / 3$ and $x_{1}=1 / 3$ as shown in panels (a) and (b) of Fig. 2, respectively.

In equilibrium each party should be indifferent between any strategies to which it assigns a strictly positive probability measure. The following lemma characterizes the unique equilibrium in mixed strategies, $\left(l^{*}, r^{*}\right)$, within the 'black hole' range.

Lemma 6. In our example, if $x_{1}=2 / 3$, there is a unique Nash equilibrium (in mixed strategies), which is given by $l^{*}=3 n_{R} / 2-1 / 2$ and $r^{*}=2-9 n_{L} / 4$. If $x_{1}=1 / 3$, $l^{*}=2-9 n_{R} / 4$ and $r^{*}=3 n_{L} / 2-1 / 2$.

Equilibrium in mixed strategies implies political instability in the 'black hole' range in the sense that parties randomize their strategies. The platform realizations of both parties are set for voting and policy is determined by a majority rule by the electorate. We turn to characterize the implemented policy for each pair of platform realizations for the case $x_{1}=2 / 3$ (again, the case $x_{1}=1 / 3$ is symmetric). Obviously, when both parties propose $P_{1}^{*}$, the implemented policy is $P_{1}^{*}$ (this scenario occurs with probability $\left.l^{*} \cdot r^{*}\right)$. Consider next the case where party $L$ proposes $P_{1}^{*}$, whereas party $R$ proposes $\bar{P}_{R}$ [the probability of which is given by $\left.l^{*} \cdot\left(1-r^{*}\right)\right]$. In such a case, it immediately follows from Tab. 3 that $P_{1}^{*}$ is implemented under majority rule, by virtue of our parametric assumptions. In the case where party $L$ proposes $\bar{P}_{L}$ whereas party $R$ proposes $P_{1}^{*}\left[\right.$ which occurs with probability $\left(1-l^{*}\right) \cdot r^{*}$, the number of supporters of party $L$ 's platform is given by $n_{L}+1 / 6$, which is bounded above by $5 / 6$ (as $n_{L}<2 / 3$ ), thus being obviously lower than the number of supporters in party $R$ 's platform. Thus, in this case $P_{1}^{*}$ is implemented again. Last, when party $L$ proposes $\bar{P}_{L}$, whereas party $R$ proposes $\bar{P}_{R}$, party $R$ is obviously the winner, as it can be observed from Tab. 3. Note that, according to Lemma 6, this occurs with probability $\left(1-l^{*}\right) \cdot\left(1-r^{*}\right)=3 / 2\left(1-n_{R}\right)\left(9 / 4 n_{L}-1\right) \equiv p\left(n_{L}, n_{R}\right)$. 
We turn next to calculate the expected utility derived by an (informed) $M$-voter, $E(u)$, based on the limiting distribution of $z=\left(S, x_{1}\right)$ (whose support is given by the set $\mathcal{Z})$.

Lemma 7. In our example, expected utility derived by a $M$-voter is given by

$$
\begin{aligned}
E(u)= & \text { Const }+\frac{0.5(1-q)}{1+2(1-q)} \times \\
& \left\{p\left(n_{R}, n_{L}\right)[\underbrace{u\left(\bar{P}_{L}, S_{1}\right)-u\left(P_{2}^{*}, S_{1}\right)}_{<0}+\underbrace{u\left(\bar{P}_{L}, S_{2}\right)-u\left(P_{2}^{*}, S_{2}\right)}_{<0}]+\right. \\
& \left.p\left(n_{L}, n_{R}\right)[\underbrace{u\left(\bar{P}_{R}, S_{1}\right)-u\left(P_{1}^{*}, S_{1}\right)}_{<0}+\underbrace{u\left(\bar{P}_{R}, S_{2}\right)-u\left(P_{1}^{*}, S_{2}\right)}_{<0}]\right\} .
\end{aligned}
$$

Within the 'black hole' range, there are four states in which a mismatch occurs with positive probability, $\left(S_{1}, 1 / 3\right),\left(S_{1}, 2 / 3\right),\left(S_{2}, 1 / 3\right)$, and $\left(S_{2}, 2 / 3\right)$. Potential mismatch states $\left(S_{1}, 1 / 3\right)$ and $\left(S_{2}, 1 / 3\right)$ are indicated by the second line of equ. (12) whereas states $\left(S_{1}, 2 / 3\right)$ and $\left(S_{2}, 2 / 3\right)$ are indicated by the last line of equ. (12). For instance, if $z=\left(S_{1}, 2 / 3\right)$, as seen above, $\bar{P}_{R}$ is chosen with probability $p\left(n_{L}, n_{R}\right)$, whereas the optimal choice $P_{1}^{*}$ occurs with $1-p\left(n_{L}, n_{R}\right)$. If $z=\left(S_{1}, 1 / 3\right)$, then $\bar{P}_{L}$ is chosen with probability $p\left(n_{R}, n_{L}\right)$ and $P_{1}^{*}$ is chosen with $1-p\left(n_{R}, n_{L}\right)$. That is, the choice is always suboptimal, but the utility loss is larger when $\bar{P}_{L}$ is chosen. (Using (10) and (11), it is easy to verify that the terms in squared brackets in equ. (12) are negative.)

Now consider an upward shift in the number of leftwing diehards, given formally by a rise in $n_{L}$. Such a change results in an increase in the probability that both parties cater to their diehards if $x_{1}=2 / 3, p\left(n_{L}, n_{R}\right)$, and a decrease in the corresponding probability if $x_{1}=1 / 3, p\left(n_{R}, n_{L}\right)$. The reason for the fact that an upward shift in number of leftwing diehards works in two opposite directions may be inferred from Fig. 2. In panel (a), which depicts the reaction functions for the case $x_{1}=2 / 3$, starting from equilibrium, when $n_{L}$ increases, party $L$, other things equal, tends to cater to its diehard constituency, thus proposing the platform $\bar{P}_{L}$ instead of mixing between $P_{1}^{*}$ and $\bar{P}_{L}$. As the reaction curve of party $L$ shifts downward (dashed line), so as to maintain the equilibrium in mixed strategies, it is necessary that party $R$ will 
increase the probability of proposing $\bar{P}_{R}$, thus balancing against the upward shift in leftwing diehards. (Formally, $p\left(n_{L}, n_{R}\right)$ is increasing with respect to $n_{L}$.) By the same token, a symmetric argument applies to the case $x_{1}=1 / 3$, where the roles reverse such that the reaction curve of party $L$ shifts upward (dashed line in panel (b) of Fig. 2 ), and equilibrium requires that party $R$ will decrease the probability assigned to $\bar{P}_{R}$, in response to a rise in $n_{L}$. (Formally, $p\left(n_{R}, n_{L}\right)$ is decreasing with respect to $n_{L}$.)

In other words, in a mixed strategy equilibrium, party $R$ is just indifferent between 'converging' (playing $P_{1}^{*}$ if $x_{1}=2 / 3$ and $P_{2}^{*}$ if $x_{1}=1 / 3$ ) and 'diverging' (playing $\bar{P}_{R}$ ). As response to an increase in $n_{L}$, which other things equal will induce divergence of party $L$, party $R$ will respond by diverging when it appeals to $M$-voters more than party $L$ does (which happens when $x_{1}=2 / 3$, hence the bulk of the $M$-voters prefer $\bar{P}_{R}$ to $\bar{P}_{L}$ ) and by converging otherwise (namely if $x_{1}=1 / 3$, hence the bulk of the $M$-voters prefer $\bar{P}_{L}$ to $\left.\bar{P}_{R}\right)$. The implication of the fact that an increase in polarization works in two opposite directions is the following.

Proposition 5. Under competition, a rise in polarization may increase social welfare.

Recall that in the monopoly case we demonstrated that a rise in polarization may be beneficial. According to Proposition 5, a rise in polarization may enhance social welfare in the competitive case as well. To see this, consider again a rise in $n_{L}$, and recall the fact that $p\left(n_{R}, n_{L}\right)$ is decreasing with respect to $n_{L}$. Setting $u\left(\bar{P}_{L}, S_{1}\right)$ low enough (and/or $u\left(P_{2}^{*}, S_{2}\right)$ high enough), other things equal, ensures that overall welfare does increase in response to a rise in $n_{L}$, as can be observed from equ. (12).

As can be seen from panel (b) of Fig. 2, polarization may be a force of policy convergence among parties, which is the ultimate reason for its potentially welfareenhancing role. This suggests that the probability that parties do not set the same platforms ('probability of divergence') may decrease with polarization. It is easy to confirm that this is indeed true. To see this, note that for a given $x_{1} \in\{1 / 3,2 / 3\}$, the probability of divergence is given by $1-l^{*} r^{*}$, i.e., the overall probability of divergence 
Figure 2

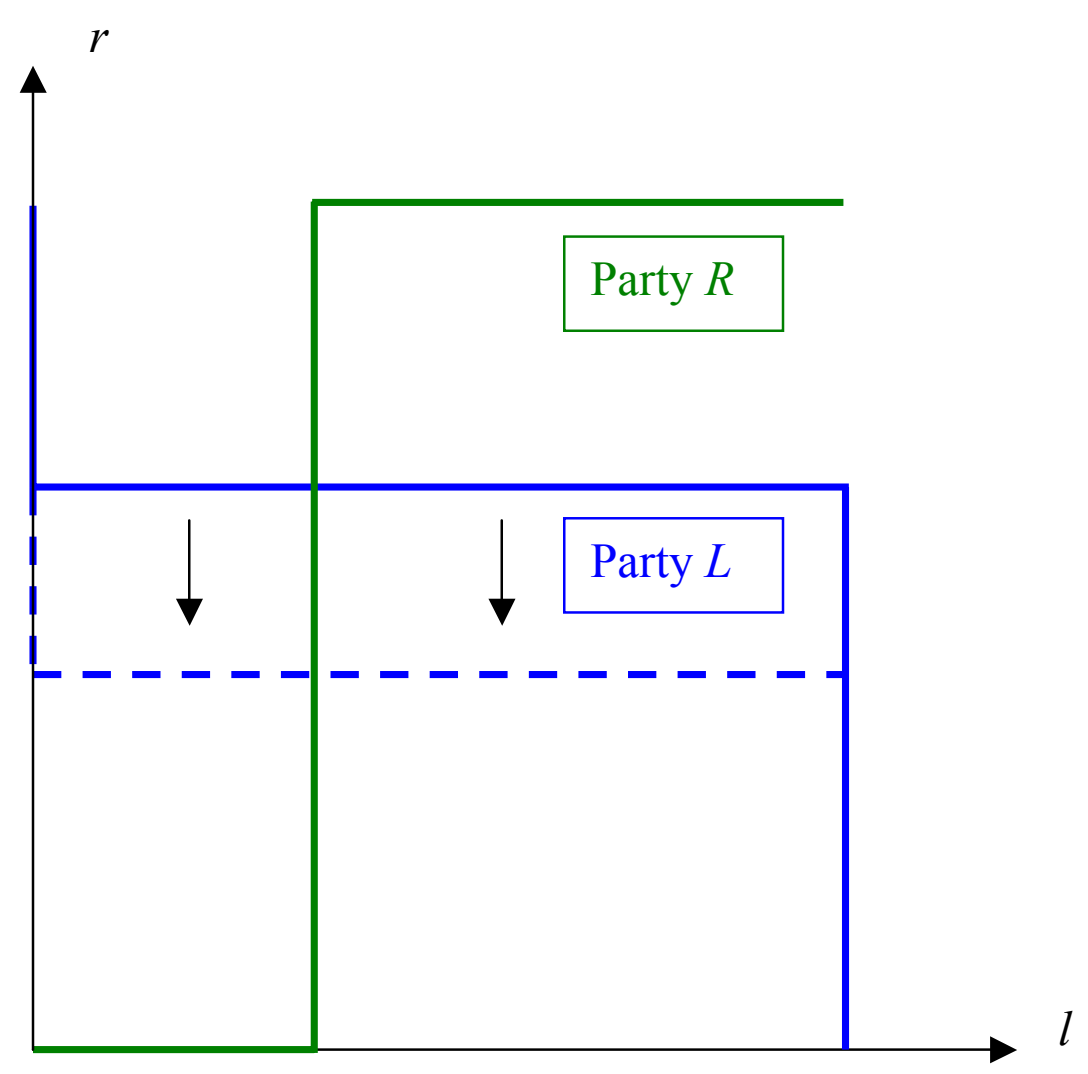

(a) $x_{1}=2 / 3$

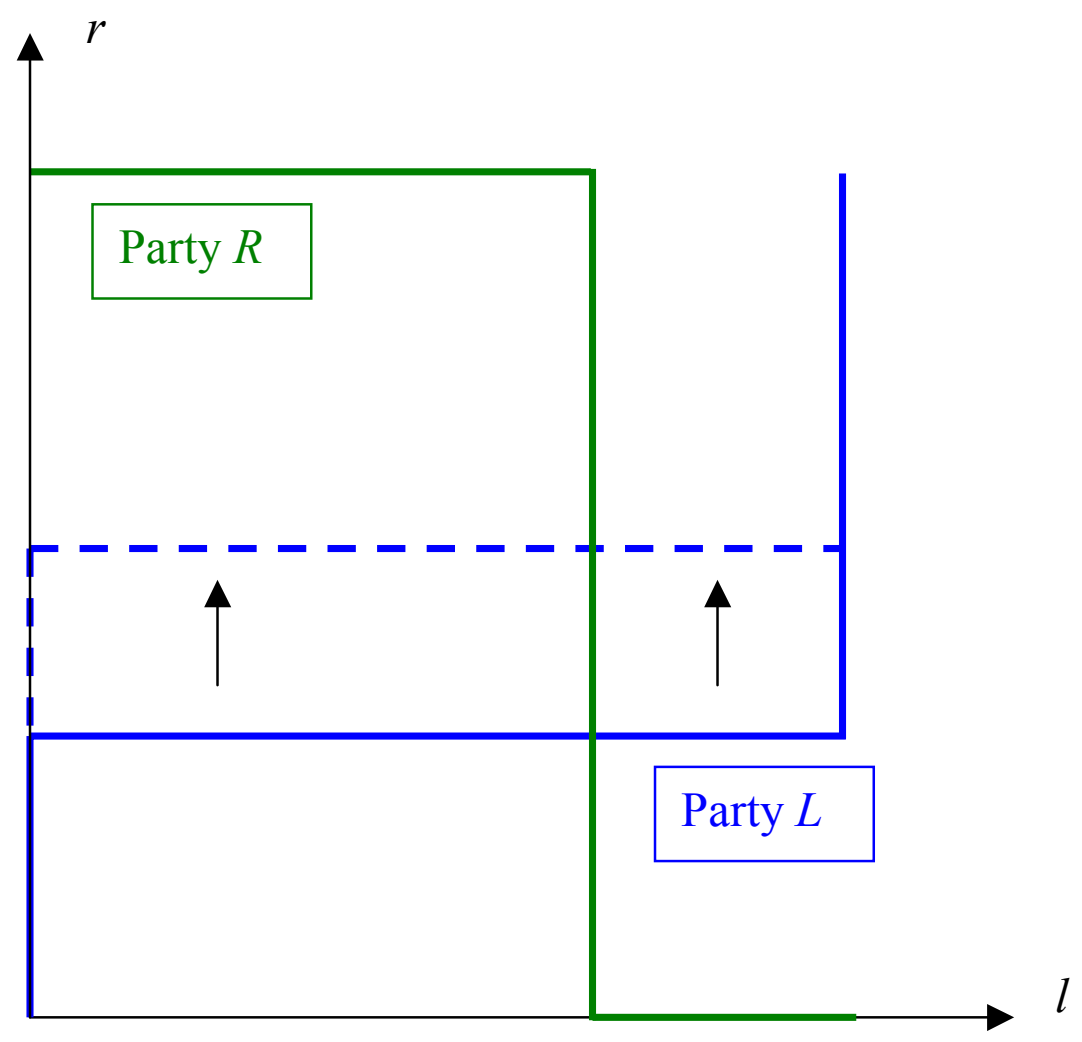

(b) $x_{1}=1 / 3$ 
is given by

$$
\Gamma\left(n_{L}, n_{R}\right) \equiv 2-\left(3 n_{R} / 2-1 / 2\right)\left(2-9 n_{L} / 4\right)-\left(2-9 n_{R} / 4\right)\left(3 n_{L} / 2-1 / 2\right),
$$

according to Lemma 6. From this, we obtain, for instance, $\partial \Gamma / \partial n_{L}<(=,>) 0$ if and only if $n_{R}<(=,>) 11 / 18$. Thus, for any $n_{R} \in(4 / 9,11 / 18)$, the probability of divergence decreases with $n_{L}$.

\section{Empirical Relevance of Diehards' Behavior}

A central building block of our model is the behavior of diehard voters. Although parties' objective functions [(2) and (3)] are also consistent with the usually vague notion of ideology-driven parties (see our discussion in section 2), we have argued that even fully Downsian parties face a trade-off in attracting their "core" constituency, who only care about ideology, and others (i.e., $M$-voters), which are characterized by their capability to process information and make voting decisions according to their perceptions about the state of the economy. In contrast, policy preferences of diehard constituencies are independent of the state of the economy but decisions whether to support their preferred party or to abstain from voting depends on their party's policy platforms. In this section we briefly discuss empirical evidence to support our main assumptions, i.e.,

(i) that party identification is to a large part driven by ideology,

(ii) that partisanship may give rise to perceptional biases which prevent a switch to the other party, irrespective of proposed platforms, and

(iii) that abstention of voters from elections is systematically related to alienation from their preferred party, depending on the distance between a voter's preferred policy and parties' proposed policy platforms.

Ad (i): Tab. 1 has given a first impression about the prevalence of ideology and party identification in the US. Not surprisingly, ideology and party identification are positively correlated. As can be seen from Tab. 5, 47.8 percent of those who report 
Table 5: Correlation table of ideology and party identification in the U.S. in 2000.

\begin{tabular}{|c|c|c|c|c|c|c|}
\hline (in percent) & $\begin{array}{c}\text { Strong } \\
\text { Democrat (1) }\end{array}$ & $\begin{array}{c}\text { Weak } \\
\text { Democrat (2) }\end{array}$ & $\begin{array}{c}\text { Independent } \\
(3-5)\end{array}$ & $\begin{array}{c}\text { Weak } \\
\text { Republican (6) }\end{array}$ & $\begin{array}{c}\text { Strong } \\
\text { Republican (7) }\end{array}$ & Total \\
\hline Extremely Liberal (1) & 47.8 & 17.4 & 30.4 & 0 & 4.4 & 100 \\
& 5.6 & 2 & 1.7 & 0 & 0.5 & 1.9 \\
Liberal (2) & 38.8 & 20.2 & 33.2 & 3.4 & 4.5 & 100 \\
Middle (3-5) & 35.2 & 18 & 14.6 & 2.8 & 3.6 & 14.4 \\
& 13.9 & 21.2 & 39.1 & 20 & 5.8 & 100 \\
Conservative (6) & 46.4 & 69.5 & 63.4 & 61.5 & 17.3 & 53.1 \\
& 5.4 & 6.4 & 23 & 22.7 & 42.5 & 100 \\
Extremely Conservative (7) & 8.7 & 10 & 17.8 & 33.3 & 60.5 & 25.4 \\
& 12.5 & 1.6 & 15.6 & 7.8 & 62.5 & 100 \\
Total & 4.1 & 0.5 & 2.5 & 2.4 & 18.2 & 5.2 \\
& 15.9 & 16.2 & 32.8 & 17.3 & 17.8 & 100 \\
& 100 & 100 & 100 & 100 & 100 & 100 \\
\hline
\end{tabular}

Data source: NES (2002).

Notes: Based on seven-point scale on ideology and party identification. The number in brackets refers to the position in this scale, i.e., the three middle categories have been condensed to one for both measures. The first (upper) number in a cell refers to the row percentage (e.g., 47.8 percent of Extreme Liberals are Strong Democrats), the second number refers to the column percentage. 
to be extremely liberal have a strong preference for the Democratic party and 65.2 percent of extreme liberals clearly support the Democrats (although not necessarily strongly). Similarly, 70.3 (62.5) percent of those who are extreme conservatives identify themselves clearly (strongly) with the Republicans. Moreover, using Tab. 1 and 5, straightforward calculation implies that 39.8 percent of those who report a clear liberal position are strong democrats, and 45.9 percent of clear conservatives are strong republicans. Interestingly, empirical evidence suggests a causal relationship running from ideology to party identification, rather than vice versa. For instance, Abramowitz and Saunders (1998) and Schreckhise and Shields (2003) find support for ideological realignment among American voters, who seem to seek a congruence between ideological positions and partisanship. ${ }^{23}$

Ad (ii): The fundamental aspect of partisanship as identification to a social group has already been pointed out in the seminal work on voting behavior by Cambell et al. (1960). Evidence by Greene (2004) suggests that strong partisans suffer from perceptional biases in evaluating their preferred party (involving mental exaggeration of their party's favorable characteristics). He also shows that social identification with a party has a substantial effect on both ideological self-placement and partisanship. ${ }^{24}$ Moreover, the overall feelings towards the non-preferred party is strongly negatively affected by a person's ideology, implying that "defection from a party may become psychologically more difficult, if indeed partisan group belonging does contribute to one's self esteem" (Greene, 2004; p. 148). This is consistent with our hypothesis that ideological voters would - irrespective of proposed policy platforms - not turn to

\footnotetext{
${ }^{23}$ Interestingly, both studies suggest that the impact of ideology on party identification has grown between the mid-1970s to the mid-1990s, whereas the impact of parental partisanship has declined. Many studies have confirmed that party identification fluctuates considerably. For instance, from the mid-1970s onwards, loyalty towards the Democrat Party has gradually declined, whereas it has risen towards the Republican Party (see, e.g., Carmines and Stanley, 1992; Abramowitz and Saunders, 1998). Moreover, although having declined in the 1960s, party identification has rebounded significantly in the 1970s, nowadays being - not surprisingly - the most effective indicator of individual vote choice (e.g., Bartels, 2000).

${ }^{24}$ Social identification relates to the average response of an individual to ten questions which measure Identification with a Psychological Group (IDGP), introduced by Mael and Tetrick (1992). The IDPG-measure is not specific to political parties but has turned out to be a reasonable concept for measuring identity for a variety of social groups.
} 
the other party. In a similar vein, using data from 10 European countries, Di Tella and MacCulloch (2004) present evidence for a strong effect of the party in power on subjective well-being ("happiness") of partisans, i.e., declared happiness is substantially higher when the preferred party is in power, and substantially lower if it is not. Also consistent with our modelling of diehard voters, Shachar (2003) concludes that partisanship involves habit formation from voting. He finds that the probability to vote for a party significantly depends on the voting choice in the previous election, even when accounting for candidates' attributes and policy stands as well as for voters' (observed and unobserved) characteristics. Finally, an intrinsic motivation to support one's preferred party is also reflected by evidence on a positive relationship between partisanship and voting participation, as reported by Fiorina (1999) and Bartels (2000), among others.

Ad (iii): The preceding evidence on partisanship and ideology does not imply, of course, that parties can be ensured of receiving support from their diehard constituency in any election. First, it has been established that even after controlling for previous party identification, issue evaluation (a variable constructed from a respondent's position matched with the subjective position of parties on a variety of issues) significantly affects party identification (Franklin, 1992). Second, consistent with our hypothesis on turnout decisions of diehards, abstention in elections is strongly determined by alienation, i.e., is a function of the distance from a voter's ideal point to the nearest candidate, as found in both presidential elections (Zipp, 1985; Adams and Merrill, 2003) and midterm elections (Plane and Gershtenson, 2004).

\section{Conclusion}

The prevalence and implications of ideological predispositions and partisanship lie at the center of the debate in the political economy and political science literature. Conventional wisdom suggests that increases in ideological polarization shifts parties away from social optimum as perceived by middle of the road voters (non-affiliated to 
parties), i.e., polarization gives rise to divergence between parties' policy platforms. Moreover, delay in desirable policy reforms has been attributed to imperfect information of voters about the state of the economy. Viewed separately, both frictions seem thus to be detrimental for welfare. Plausibly assuming that frictions in the process of information diffusion exist, however, our analysis has shown that a shift in ideological polarization may increase welfare by mitigating the effects of information stickiness.

We have demonstrated the potential welfare-enhancing role of increased polarization under different regimes differing in the degree of political competition, emphasizing its two-way effect on the likelihood of desirable reforms responding to changes in the economic fundamentals. We examined two cases, the first in which a single strategic party is setting its platform optimally, given a fixed platform of the other (passive) party, and a second more compelling one in which a full-fledged competition between the two parties takes place. In the former case we have shown that increased polarization may be welfare-enhancing as it not only gives rise to a delay in desirable reforms opposed by the strategic party's core constituency, but also speeds up called-for delayed reforms in the opposite direction. In the perhaps more relevant case of two competing parties, our analysis suggests that policy platforms converge if there is sufficient consensus among voters about the state of the economy, whereas ideological polarization matters for policy platforms in absence of such consensus. We have demonstrated that, in the latter case, shifts in polarization give rise to strategic effects which may reduce the probability of policy divergence. In turn, this converging force allows for a potentially welfare-enhancing role of ideological polarization, when it outweighs the adverse implications of the diverging force singled out by the existing body of literature. 


\section{Appendix}

\section{A. Proofs}

Proof of Proposition 1: According to Lemma 1, there are three intervals to consider. Note that within each interval the number of $M$-voters is fixed. Thus, we can solve the maximization of party $L$ in two stages. First, for each interval we choose the platform which maximizes the number of diehard voters, being the leftmost point of each interval, according to our assumption that $\hat{P}_{L}=\min \left(P, P^{\prime}\right)$ if $\pi_{L}\left(P, \bar{P}_{R}\right)=\pi_{L}\left(P^{\prime}, \bar{P}_{R}\right)$. In the second stage, we choose amongst the intervals. Formally, $\hat{P}_{L} \in\left\{\bar{P}_{L}, P_{2}^{\min }\left(\bar{P}_{R}\right), P_{1}^{\min }\left(\bar{P}_{R}\right)\right\}$. Note that by virtue of our assumption that $M$-voters support party $L$ when being indifferent between platforms set by the two parties, we have $\hat{P}_{L}=\bar{P}_{L}$ if $\pi_{L}\left(\bar{P}_{L}, \bar{P}_{R}\right)=\pi_{L}\left(P_{i}^{\min }\left(\bar{P}_{R}\right), \bar{P}_{R}\right), i=1,2$, and $\hat{P}_{L}=P_{2}^{\min }\left(\bar{P}_{R}\right)$ if $\pi_{L}\left(P_{2}^{\min }\left(\bar{P}_{R}\right), \bar{P}_{R}\right)=\pi_{L}\left(P_{1}^{\min }\left(\bar{P}_{R}\right), \bar{P}_{R}\right)$. Also note that when $P_{2}^{\min }\left(\bar{P}_{R}\right)>\bar{P}_{L}$ and $F_{L}\left(P_{1}^{\min }\left(\bar{P}_{R}\right)-\bar{P}_{L}\right) n_{L}<1$, a deviation from $\bar{P}_{L}$ to $P_{1}^{\min }\left(\bar{P}_{R}\right)$ is profitable. In such a case $\bar{P}_{L}$ is suboptimal, and we only need to consider the two other possibilities, namely, $P_{2}^{\min }\left(\bar{P}_{R}\right)$ and $P_{1}^{\min }\left(\bar{P}_{R}\right)$. (The latter holds trivially, when $\bar{P}_{L}=P_{2}^{\min }\left(\bar{P}_{R}\right)$.) A switch from $P_{2}^{\min }\left(\bar{P}_{R}\right)$ to $P_{1}^{\min }\left(\bar{P}_{R}\right)$ would be profitable if the benefit ( $M$-voters who believe in $S_{1}$ ) outweighs the costs (a loss of diehards). Formally, this is the case when $x_{1}>c\left(\bar{P}_{R}, \bar{P}_{L}, n_{L}\right)$, and vice versa. If $x_{1}=c\left(\bar{P}_{R}, \bar{P}_{L}, n_{L}\right)$, then party $L$ chooses $P_{2}^{\min }\left(\bar{P}_{R}\right)$, since $P_{2}^{\min }\left(\bar{P}_{R}\right)$ is closer to $P_{1}^{\min }\left(\bar{P}_{R}\right)$ under A1. This concludes the proof.

Proof of Lemma 2: First, let us define $p_{i, k} \equiv \operatorname{prob}\left\{z=\left(S_{i}, k / K\right)\right\}, k=$ $0,1, \ldots, K$. (For notional simplicity, we omit the time index $t$.) Note that $p_{1,0}=$ $p_{2, K}=0$, since at least a mass $1 / K$ of the $M$-voters is correctly informed about the actual state of the economy at any date, according to (1). Thus,

$$
\sum_{k=1}^{K}\left(p_{1, k}+p_{2, k-1}\right)=1
$$

must hold. Next, we derive further relationships between the probabilities of all 
possible values of the state variable $z^{t}$ as $t \rightarrow \infty$. This stochastic process is a random walk with two absorbing states, $\left(S_{1}, 1\right)$ and $\left(S_{2}, 0\right)$. According to $(1)$, there are three possibilities to be in state $\left(S_{1}, 1\right)$. Either we have been in $\left(S_{1}, 1\right)$ or $\left(S_{2},(K-1) / K\right)$ in the previous period and the economy stayed in $S_{1}$, which happens with probability $q$, or we have been in $\left(S_{1},(K-1) / K\right)$ and switched to $\left(S_{1}, 1\right)$, which happens with probability $1-q$. Thus, the relationship

$$
p_{1, K}=q\left(p_{1, K-1}+p_{1, K}\right)+(1-q) p_{2, K-1}
$$

must hold. Similarly, there are three possibilities to be in state $\left(S_{2}, 0\right)$. Either we have been in $\left(S_{2}, 0\right)$ or $\left(S_{2}, 1 / K\right)$ before and the economy stayed in $S_{2}$ (with probability $q$ ), or we have been in $\left(S_{1}, 1 / K\right)$ and switched to $\left(S_{2}, 0\right)$, which happens with probability $1-q$. Thus,

$$
p_{2,0}=q\left(p_{2,0}+p_{2,1}\right)+(1-q) p_{1,1}
$$

Moreover, symmetry implies

$$
p_{1, K}=p_{2,0} \equiv \hat{p}
$$

Now consider state $\left(S_{1}, 1 / K\right)$. The only possibility to be in this state is that state $\left(S_{2}, 0\right)$ prevailed in the previous period, and the state of the economy switched from $S_{2}$ to $S_{1}$, which happens with probability $1-q$. Thus, $p_{1,1}=(1-q) p_{2,0}$. Similarly, being in state $\left(S_{2},(K-1) / K\right)$ is only possible if state $\left(S_{1}, 1\right)$ prevailed in the previous period, and the state of the economy switched from $S_{1}$ to $S_{2}$, which also happens with probability $1-q$. Using (A.4), we thus find the relationships

$$
p_{1,1}=p_{2, K-1}=(1-q) \hat{p} .
$$

Next, consider states $\left(S_{1}, k / K\right), k=2, \ldots, K-1$. To be in state $\left(S_{1}, k / K\right)$ requires either that the economy stayed in $S_{1}$ (with probability $q$ ), i.e., the previous state was $\left(S_{1},(k-1) / K\right)$, or moved from $\left(S_{2},(k-1) / K\right)$ to $\left(S_{1}, k / K\right)$, which happens with 
probability $1-q$. Thus, the relationships

$$
p_{1, k}=q p_{1, k-1}+(1-q) p_{2, k-1}, k=2, \ldots, K-1
$$

must hold. Similarly, to be in state $\left(S_{2}, k / K\right), k=1, \ldots, K-2$, requires either that the economy stayed in $S_{2}$ (with probability $q$ ), i.e., the previous state was $\left(S_{2},(k+1) / K\right)$, or moved from $\left(S_{1},(k+1) / K\right)$ to $\left(S_{2}, k / K\right)$, which happens with probability $1-q$. Thus,

$$
p_{2, k}=q p_{2, k+1}+(1-q) p_{1, k+1}, k=1, \ldots, K-2 .
$$

We now use (A.1)-(A.7) to solve for the $2 K$ unknowns $p_{1, k}, p_{2, k-1}, k=1, \ldots, K .^{25}$ First, combining (A.2) and (A.4) yields $\hat{p}=p_{1, K-1} q /(1-q)+p_{2, K-1}$. Thus, using $p_{2, K-1}=(1-q) \hat{p}$ from $(\mathrm{A} .5)$, we obtain $p_{1, K-1}=(1-q) \hat{p}$. Now, using (A.7) for $k=K-2$, i.e., $p_{2, K-2}=q p_{2, K-1}+(1-q) p_{1, K-1}$, and using both $p_{2, K-1}=(1-q) \hat{p}$ and $p_{1, K-1}=(1-q) \hat{p}$ yields $p_{2, K-2}=(1-q) \hat{p}$. In analogous considerations, one can show that in fact $p_{i, k}=(1-q) \hat{p}$ for all $i=1,2, k=1, \ldots, K-1$, which confirms (7). Substituting this and (A.4) into (A.1), we obtain $2 \hat{p}+2(K-1)(1-q) \hat{p}=1$, which yields (6). This concludes the proof.

Proof of Proposition 2. First, we calculate the probabilities $\alpha_{2,1}$ and $\alpha_{1,2}$. (Recall that $\alpha_{1,1}=0.5-\alpha_{2,1}$ and $\alpha_{2,2}=0.5-\alpha_{1,2}$.) If $k / K \leq c<(k+1) / K$, $k=1, \ldots, K-1$, then there are exactly $k$ events in which the state of the economy is $S_{1}$ and $x_{1} \leq c$, i.e., $P_{2}^{\min }$ is chosen, according to part (c) of Proposition 1. ${ }^{26}$ Thus, using Lemma 2, we have $\alpha_{2,1}=k(1-q) \hat{p}$ if $k / K \leq c<(k+1) / K, k=1, \ldots, K-1$. Similarly, there are exactly $K-1-k$ events in which the state of the economy is $S_{2}$ and $x_{1}>c$, i.e., $P_{1}^{\min }$ is chosen. (Recall that $c \in(0,1)$ under assumption $\mathrm{A} 1$ and presumption $F_{L}\left(P_{1}^{\min }\left(\bar{P}_{R}\right)-\bar{P}_{L}\right) n_{L}<1$.) If $c<1 / K$, then $P_{1}^{\min }$ is chosen whenever $x_{1}>0$. Thus, if $c<1 / K$, there is no mismatch if $S=S_{1}$ (i.e., $\mathcal{Z}_{2,1}=\emptyset$ ), but hence, except for the case $x_{1}=0$, there is always a mismatch if $S=S_{2}$ (i.e., there are $K-1$

\footnotetext{
${ }^{25}$ Note that (A.1)-(A.7) give us $2 K+2$ equations. One can show that two relationships are indeed redundant, due to the interdependency of the transition probabilities.

${ }^{26}$ These events are $\left(S_{1}, 1 / K\right), \ldots,\left(S_{1}, k / K\right)$. Recall that $\left(S_{1}, 0\right)$ is impossible, i.e., $p_{1,0}=0$.
} 
elements in $\left.\mathcal{Z}_{1,2}\right)$. In sum, using Lemma 2 , we have for all $k=1, \ldots, K-1$ :

$$
\alpha_{2,1}=\left\{\begin{array}{c}
0 \text { if } c<\frac{1}{K}, \\
\frac{0.5 k(1-q)}{1+(K-1)(1-q)} \text { if } \frac{k}{K} \leq c<\frac{k+1}{K},
\end{array}\right.
$$

and

$$
\alpha_{1,2}=\left\{\begin{array}{c}
\frac{0.5(K-1)(1-q)}{1+(K-1)(1-q)} \text { if } c<\frac{1}{K}, \\
\frac{0.5(K-1-k)(1-q)}{1+(K-1)(1-q)} \text { if } \frac{k}{K} \leq c<\frac{k+1}{K} .
\end{array}\right.
$$

Now consider comparative-statics with respect to changes in $K$ (parts (i) of (a) and (b) of Proposition 2). Since party $L$ chooses $P_{2}^{\min }$ if $x_{1}=0$ and $P_{1}^{\min }$ if $x_{1}=1$, perfect information $(K=1)$ implies $\alpha_{1,2}=\alpha_{2,1}=0$. Thus, $E(u)=\beta$ if $K=1$, according to (8). If $K>1$, however, either $\alpha_{2,1}>0$ or $\alpha_{1,2}>0$ or both, according to (A.8) and (A.9). Thus, if $\Delta_{1,2}<0$ holds (in addition to $\Delta_{2,1}<0$ ), $E(u)<\beta$ if $K>1$ (part (a)). If $\Delta_{1,2}>0$ (part (b)), however, welfare may be higher if $K>1$ than if $K=1$. Indeed, this holds whenever $\alpha_{1,2} \Delta_{1,2}>-\alpha_{2,1} \Delta_{2,1}$, according to (8). Using that both sides of this inequality are strictly positive under presumption $\Delta_{1,2}>0$, if $\alpha_{1,2}>0$, $\alpha_{2,1}>0$ and $K>1$, confirms the claim. Analogously, it is also easy to show, by using (A.8) and (A.9), that welfare may rise after an increase from $K>1$ to $\tilde{K}>K$ when $\Delta_{1,2}>0$. It remains to be shown how welfare changes in the case $\Delta_{1,2}<0$ after an increase from $K>1$ to $\tilde{K}=K+1$. Denote the welfare level after such a change by $\tilde{E}(u)$. Now consider the case in which the number of elements in, say, $\mathcal{Z}_{2,1}$ remains unchanged when $K$ changes (given $c$ ), denoted by $\bar{\kappa}$. Then

$$
E(u)=\frac{0.5 \bar{\kappa}(1-q)}{1+(K-1)(1-q)} \Delta_{2,1}+\frac{0.5(K-1-\bar{\kappa})(1-q)}{1+(K-1)(1-q)} \Delta_{1,2}+\beta
$$

and

$$
\tilde{E}(u)=\frac{0.5 \bar{\kappa}(1-q)}{1+K(1-q)} \Delta_{2,1}+\frac{0.5(K-\bar{\kappa})(1-q)}{1+K(1-q)} \Delta_{1,2}+\beta,
$$

according to (A.8), (A.9) and (8). Observing that $\Delta_{1,2}<0$, it is straightforward to show that $\tilde{E}(u)<E(u)$ if and only if $\Delta_{2,1} / \Delta_{1,2}<1+1 /[\bar{\kappa}(1-q)]$. Since $\bar{\kappa} \leq K-1$, this holds if $\Delta_{2,1} / \Delta_{1,2}<1+1 /[(K-1)(1-q)]$. In a similar fashion, one could assume 
that the number of elements in $\mathcal{Z}_{1,2}$ remain unchanged. In sum, we then obtain that $\tilde{E}(u)<E(u)$ if

$$
\frac{\min \left\{\Delta_{2,1}, \Delta_{1,2}\right\}}{\max \left\{\Delta_{2,1}, \Delta_{1,2}\right\}}<1+\frac{1}{(K-1)(1-q)},
$$

which holds for any $\left\{\Delta_{2,1}, \Delta_{1,2}\right\}$ if $K$ is sufficiently small. ${ }^{27}$ This confirms parts (i) of (a) and (b).

Now we turn to the proof of parts (ii) of (a) and (b). Note from (A.8) and (A.9) that, if anything, $\alpha_{2,1}$ increases and $\alpha_{1,2}$ decreases after an increase in $n_{L}$ (which implies an increase in $c$ ). Thus, there are generally counteracting effects of an increase in $n_{L}$ on $E(u)$ if $\Delta_{1,2}<0$, according to (8), leaving the impact on welfare generally ambiguous as stated in part (a). However, when $\Delta_{1,2}>0$, if anything, the terms $\alpha_{2,1} \Delta_{2,1}$ and $\alpha_{1,2} \Delta_{1,2}$ decrease with $n_{L}$. Thus, $E(u)$ decreases with $n_{L}$ as stated in part (b).

Finally, consider an increase in $q$. Note that $\partial \alpha_{2,1} / \partial q<0$ and $\partial \alpha_{1,2} / \partial q \leq 0$ (with strict inequality if $c<(K-1) / K)$, according to (A.8) and (A.9), respectively. Parts (iii) of (a) and (b) then directly follow from expression (8) for expected utility. This concludes the proof.

Proof of Lemma 3: Let, without loss of generality, $P_{1}^{*} \geq P_{2}^{*}$. First, consider the behavior of party $L$ in response to $P_{R} \in\left(P_{1}^{*}, \bar{P}_{R}\right]$. Note that it may be optimal to set $P_{L}=\bar{P}_{L}$ (e.g., when $n_{L}$ is high). Also note that, if $x_{i}>0$, setting $P_{L}$ slightly above $P_{i}^{\min }\left(P_{R}\right)$ is always preferred to $P_{L}=P_{i}^{\min }\left(P_{R}\right), i=1,2$. To see the latter, note that choosing $P_{L}$ slightly above $P_{i}^{\min }\left(P_{R}\right)$ attracts at least a mass $x_{i}$ of $M$-voters, whereas setting $P_{L}=P_{i}^{\min }\left(P_{R}\right)$ attracts only $0.5 x_{i}$ of $M$-voters with perception $\hat{S}=S_{i}$, $i=1,2$, by virtue of our assumption that half of the $M$-voters go to either party when being indifferent between the policy proposals of the two parties. The cost in terms of diehards when deviating slightly from $P_{i}^{\min }\left(P_{R}\right)$, however, is marginal (by continuity of $F_{L}(\gamma)$ ). But since policy space $\mathcal{P}$ is continuous, if choosing $P_{L}$ slightly above $P_{i}^{\min }\left(P_{R}\right)$ yields a higher payoff than $\pi_{L}\left(\bar{P}_{L}, P_{R}\right)$, then there does not exist

\footnotetext{
${ }^{27}$ Note that it trivially follows for $K=1$, and that, for $\Delta_{2,1}=\Delta_{1,2}$, it holds for all $K$.
} 
a best response to $P_{R} \in\left(P_{1}^{*}, \bar{P}_{R}\right]$. By an analogous argument, if $P_{R} \in\left[\bar{P}_{L}, P_{2}^{*}\right)$, then $P_{R}=\bar{P}_{R}$ is the only candidate for a best response of party $R$. This implies that $P_{y}=\bar{P}_{y}, y=L, R$, may be an equilibrium, but no strategy pair such that $P_{R} \in\left(P_{1}^{*}, \bar{P}_{R}\right)$ or $P_{R} \in\left(\bar{P}_{L}, P_{2}^{*}\right)$. Second, if $P_{R}=P_{1}^{*}$, the optimal response of party $L$ may be $P_{1}^{*}$ or $\bar{P}_{L}$. Given $P_{L}=\bar{P}_{L}$, we have already seen that $P_{R}=\bar{P}_{R}$ is the only candidate for a best response of party $R$. Also note that by a similar argument as used above, setting $P_{L}$ slightly above $P_{2}^{\min }\left(P_{1}^{*}\right)$ is always preferred to $P_{L}=P_{2}^{\min }\left(P_{1}^{*}\right)$ if $x_{2}>0$. (If $x_{2}=0$, party $L$ cannot gain from deviating from $P_{1}^{*}$ or $\bar{P}_{L}$, respectively, in response to $P_{R}=P_{1}^{*}$.) Thus, if $P_{R}=P_{1}^{*}$, then no other strategy than $P_{L}=P_{1}^{*}$ can be part of an equilibrium. The same holds vice versa. Similarly, if $P_{R}=P_{2}^{*}$, then no other strategy than $P_{L}=P_{2}^{*}$ can be part of an equilibrium, and vice versa. This concludes the proof.

Proof of Lemma 4: First, we show that in a pure strategy Nash equilibrium with $P_{L}=P_{R}=P_{i}^{*}$, we have $x_{i}>0.5, i=1,2$. For instance, suppose to the contrary that $P_{L}=P_{R}=P_{1}^{*}$ is an equilibrium and $x_{1} \leq 0.5$. Now consider a deviation of party $L$ to $P_{L} \in\left(P_{2}^{*}, P_{1}^{*}\right)$. In this case, party $L$ would gain a mass $x_{2}-0.5=0.5-x_{1}$ of $M$-voters under A2, in addition to a strictly positive mass of diehards. (Recall $\bar{\gamma} \geq \bar{P}_{R}-\bar{P}_{L}$.) Thus, if $x_{1} \leq 0.5$, it cannot be an equilibrium that both parties set $P_{1}^{*}$. Analogously, $P_{L}=P_{R}=P_{2}^{*}$ cannot be an equilibrium if $x_{2}=1-x_{1} \leq 0.5$.

For the next step, again, suppose $P_{L}=P_{R}=P_{1}^{*}$. If party $R$ deviates by moving to $\bar{P}_{R}$, it (exactly) gains a mass $n_{R}-\left(\left[1-F_{R}\left(\bar{P}_{R}-P_{1}^{*}\right)\right] n_{R}+0.5\right)$ of voters (under assumption A2). Thus, if $F_{R}\left(\bar{P}_{R}-P_{1}^{*}\right) n_{R}>0.5$ it would be profitable to do so. Analogously, if party $L$ moves to $\bar{P}_{L}$, it at least gains $n_{L}-\left(\left[1-F_{L}\left(P_{1}^{*}-\bar{P}_{L}\right)\right] n_{L}+0.5\right)$. Thus, conditions $F_{R}\left(\bar{P}_{R}-P_{1}^{*}\right) n_{R} \leq 0.5$ and $F_{L}\left(P_{1}^{*}-\bar{P}_{L}\right) n_{L} \leq 0.5$ are both necessary for $P_{L}=P_{R}=P_{1}^{*}$ to be an equilibrium. In an analogous way, it is easy to see that both $F_{R}\left(\bar{P}_{R}-P_{2}^{*}\right) n_{R} \leq 0.5$ and $F_{L}\left(P_{2}^{*}-\bar{P}_{L}\right) n_{L} \leq 0.5$ are necessary for $P_{L}=P_{R}=P_{2}^{*}$ to be an equilibrium. This concludes the proof.

Proof of Lemma 5. First, recall from Lemma 3 that $P_{y}=\bar{P}_{y}$ for $y=L, R$ and 
$P_{L}=P_{R} \in\left\{P_{1}^{*}, P_{2}^{*}\right\}$ are the only candidates for Nash equilibria in pure strategies. Lemma 5 is proven by distinguishing all possible scenarios regarding the relationship of utility of $M$-voters, $u(P, S), S \in \mathcal{S}$, at different policies $P \in\left\{\bar{P}_{L}, \bar{P}_{R}\right\}$.

Scenario 1: First, suppose that $M$-individuals are strictly better off under platform $\bar{P}_{R}$ than under $\bar{P}_{L}$ if the state of the economy is $S_{i}$ but vice versa if it is $S_{i^{\prime}}$, $i^{\prime} \neq i$; e.g., let

$$
u\left(\bar{P}_{L}, S_{1}\right)<u\left(\bar{P}_{R}, S_{1}\right) \text { and } u\left(\bar{P}_{L}, S_{2}\right)>u\left(\bar{P}_{R}, S_{2}\right)
$$

Then both $P_{1}^{\min }\left(\bar{P}_{R}\right)>\bar{P}_{L}=P_{2}^{\min }\left(\bar{P}_{R}\right)$ and $P_{2}^{\max }\left(\bar{P}_{L}\right)<\bar{P}_{R}=P_{1}^{\max }\left(\bar{P}_{L}\right)$ hold, as can be seen from Fig. 3. Now suppose $P_{L}=\bar{P}_{L}$ and $P_{R}=\bar{P}_{R}$. Then party $L$ attracts a fraction $x_{2}=1-x_{1}$ of $M$-individuals, whereas party $R$ attracts the remaining fraction $x_{1}$. Now, for instance, if party $L$ deviates by proposing a platform slightly above $P_{1}^{\min }\left(\bar{P}_{R}\right)$ (given $\left.P_{R}=\bar{P}_{R}\right)$ it attracts all $M$-voters. Thus, $\bar{P}_{L}$ is the (unique) optimal response to $\bar{P}_{R}$ if and only if $n_{L}+x_{2} \geq\left[1-F_{L}\left(P_{1}^{\min }\left(\bar{P}_{R}\right)-\bar{P}_{L}\right)\right] n_{L}+1$, which is equivalent to $F_{L}\left(P_{1}^{\min }\left(\bar{P}_{R}\right)-\bar{P}_{L}\right) n_{L} \geq 1-x_{2}=x_{1}$. Similarly, for party $R$, $\bar{P}_{R}$ is the (unique) optimal response to $\bar{P}_{L}$ if and only if $F_{R}\left(\bar{P}_{R}-P_{2}^{\max }\left(\bar{P}_{L}\right)\right) n_{R} \geq$ $1-x_{1}=x_{2}$. Now note that $P_{1}^{\min }\left(\bar{P}_{R}\right)<P_{1}^{*}$ and $P_{2}^{\max }\left(\bar{P}_{L}\right)>P_{2}^{*}$ (see Fig. 3). Thus, if $P_{L}=P_{R}=P_{1}^{*}$ is a Nash equilibrium, i.e., $x_{1}>0.5$ and $F_{L}\left(P_{1}^{*}-\bar{P}_{L}\right) n_{L} \leq 0.5$, according to Lemma 4 , it is impossible that $F_{L}\left(P_{1}^{\min }\left(\bar{P}_{R}\right)-\bar{P}_{L}\right) n_{L} \geq x_{1}>0.5$ holds at the same time. Similarly, if $P_{L}=P_{R}=P_{2}^{*}$ in Nash equilibrium (such that $x_{2}>0.5$ and $F_{R}\left(\bar{P}_{R}-P_{2}^{*}\right) n_{R} \leq 0.5$, according to Lemma 4$)$ it is impossible that $F_{R}\left(\bar{P}_{R}-\right.$ $\left.P_{2}^{\max }\left(\bar{P}_{L}\right)\right) n_{R} \geq x_{2}>0.5$ holds at the same time. However, if $P_{y}=\bar{P}_{y}$ for $y=L, R$ is a Nash equilibrium for some $x_{1} \in[0,1]$, then either $F_{L}\left(P_{1}^{\min }\left(\bar{P}_{R}\right)-\bar{P}_{L}\right) n_{L} \geq 0.5$ or $F_{R}\left(\bar{P}_{R}-P_{2}^{\max }\left(\bar{P}_{L}\right)\right) n_{R} \geq 0.5$ must hold, with strict inequality if $x_{1} \neq 0.5$. Thus, for any $x_{1}$ such that $P_{y}=\bar{P}_{y}$ for $y=L, R$ is a Nash equilibrium, at least one necessary condition for $P_{L}=P_{R}=P_{i}^{*}$ to be an equilibrium is violated, $i=1,2$. It is easy to check that analogous arguments apply if $u\left(\bar{P}_{L}, S_{1}\right)>u\left(\bar{P}_{R}, S_{1}\right)$ and $u\left(\bar{P}_{L}, S_{2}\right)<u\left(\bar{P}_{R}, S_{2}\right) \cdot{ }^{28}$

\footnotetext{
${ }^{28}$ To see this, note that if $P_{y}=\bar{P}_{y}$ for $y=L, R$ is a Nash equilibrium, then both $F_{L}\left(P_{2}^{\min }\left(\bar{P}_{L}\right)-\right.$
} 
Figure 3
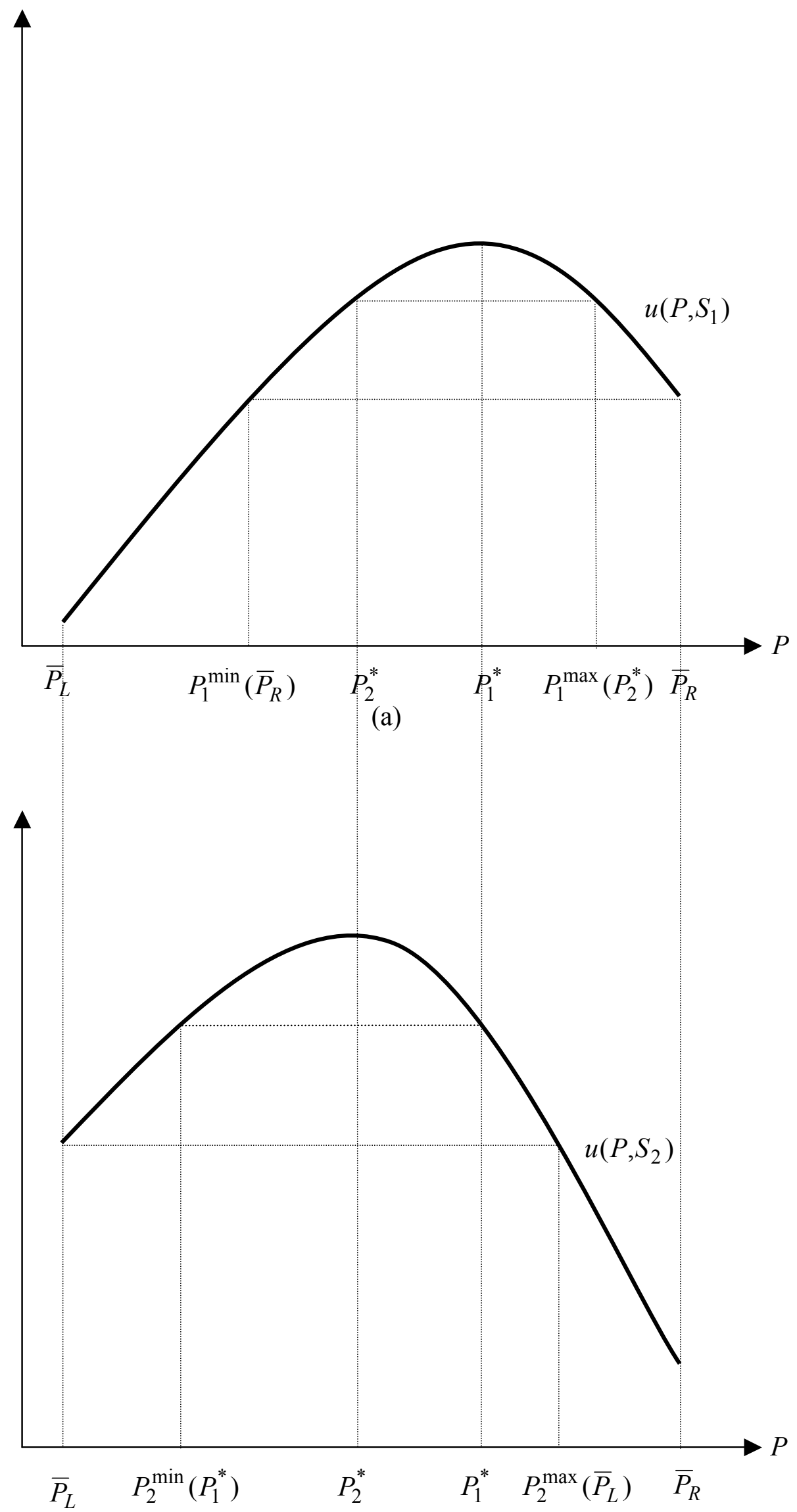

(b) 
Scenario 2: Next suppose $u\left(\bar{P}_{L}, S_{i}\right)<u\left(\bar{P}_{R}, S_{i}\right)$ for $i=1,2$. That is, if $P_{L}=\bar{P}_{L}$ and $P_{R}=\bar{P}_{R}$, then party $L$ gets $n_{L}$ votes, whereas party $R$ gets $n_{R}+1$ votes. (Again, the following arguments apply in a similar way to the opposite case in which $u\left(\bar{P}_{L}, S_{i}\right)>u\left(\bar{P}_{R}, S_{i}\right)$ for $i=1,2$.) Now, given $P_{R}=\bar{P}_{R}$, party $L$ can attract at least a mass $x_{i}$ of $M$-voters (who believe that the state of the economy is $S_{i}$ ) by choosing $P_{L}$ slightly above $P_{i}^{\min }\left(\bar{P}_{R}\right)$. Thus, for $P_{L}=\bar{P}_{L}$ being the optimal response to $P_{R}=\bar{P}_{R}$, it is necessary that $n_{L} \geq\left[1-F_{L}\left(P_{i}^{\min }\left(\bar{P}_{R}\right)-\bar{P}_{L}\right)\right] n_{L}+x_{i}$ for $i=1,2$. That is, $F_{L}\left(P_{1}^{\min }\left(\bar{P}_{R}\right)-\bar{P}_{L}\right) n_{L} \geq x_{1}$ and $F_{L}\left(P_{2}^{\min }\left(\bar{P}_{R}\right)-\bar{P}_{L}\right) n_{L} \geq 1-x_{1}$ must hold simultaneously. Now note that $P_{1}^{\min }\left(\bar{P}_{R}\right)<P_{1}^{*}$ and $P_{2}^{\min }\left(\bar{P}_{R}\right)<P_{2}^{*}$. Thus, if the presumptions of Lemma 4 hold and $P_{L}=P_{R}=P_{i}^{*}$ is a Nash equilibrium for some $x_{i}(>0.5), i=1,2$, it is impossible that $P_{y}=\bar{P}_{y}$ for $y=L, R$ is a Nash equilibrium at the same time. Vice versa, if $P_{y}=\bar{P}_{y}$ for $y=L, R$ is a Nash equilibrium for some $x_{1}$, then either $F_{L}\left(P_{1}^{\min }\left(\bar{P}_{R}\right)-\bar{P}_{L}\right) n_{L} \geq 0.5$ or $F_{L}\left(P_{2}^{\min }\left(\bar{P}_{L}\right)-\bar{P}_{L}\right) n_{L} \geq 0.5$ must hold, with strict inequality if $x_{1} \neq 0.5$. Thus, for any $x_{1}$ such that $P_{y}=\bar{P}_{y}$ for $y=L, R$ is a Nash equilibrium, at least one necessary condition for $P_{L}=P_{R}=P_{i}^{*}$ to be an equilibrium is violated, $i=1,2$, according to Lemma 4 .

Scenario 3: Finally, consider the case in which $u\left(\bar{P}_{L}, S_{i}\right)=u\left(\bar{P}_{R}, S_{i}\right)$ for at least one $i=1,2$. In this case, given $P_{R}=\bar{P}_{R}$, a slight deviation of party $L$ from $\bar{P}_{L}$ yields a gain of at least a mass $0.5 x_{i}$ of $M$-voters, whereas the loss of diehards is marginal by continuity of $F_{L}$. Thus, if $u\left(\bar{P}_{L}, S_{i}\right)=u\left(\bar{P}_{R}, S_{i}\right)$ for all $i=1,2$, the strategy pair $P_{y}=\bar{P}_{y}, y=L, R$, cannot be an equilibrium. If, say, $u\left(\bar{P}_{L}, S_{1}\right)=u\left(\bar{P}_{R}, S_{1}\right)$ and $u\left(\bar{P}_{L}, S_{2}\right)<u\left(\bar{P}_{R}, S_{2}\right)$, for $\bar{P}_{L}$ being the optimal response to $P_{R}=\bar{P}_{R}$, it is necessary that both $x_{1}=0$ and $F_{L}\left(P_{2}^{\min }\left(\bar{P}_{R}\right)-\bar{P}_{L}\right) n_{L} \geq 1-0.5 x_{1}$ simultaneously hold. Thus, $x_{1}=0$ and $F_{L}\left(P_{2}^{\min }\left(\bar{P}_{R}\right)-\bar{P}_{L}\right) n_{L} \geq 1$ must hold. In this case, however, neither $P_{L}=P_{R}=P_{1}^{*}$ nor $P_{L}=P_{R}=P_{2}^{*}$ can be a Nash equilibrium, since necessary condition $x_{1}>0.5$ is violated for the former and $F_{L}\left(P_{2}^{*}-\bar{P}_{L}\right) n_{L} \leq 0.5$ is violated for the latter $\left(\right.$ recall $\left.P_{2}^{*}>P_{2}^{\min }\left(\bar{P}_{R}\right)\right)$. Similar arguments hold whenever $u\left(\bar{P}_{L}, S_{i}\right)=u\left(\bar{P}_{R}, S_{i}\right)$ for $\overline{\left.\bar{P}_{L}\right) n_{L} \geq x_{2} \text { and } F_{R}\left(\bar{P}_{R}-P_{1}^{\max }\left(\bar{P}_{L}\right)\right) n_{R}} \geq x_{1}$ must hold if $u\left(\bar{P}_{L}, S_{1}\right)>u\left(\bar{P}_{R}, S_{1}\right)$ and $u\left(\bar{P}_{L}, S_{2}\right)<$ $u\left(\bar{P}_{R}, S_{2}\right)$. Also note that $P_{1}^{\max }\left(\bar{P}_{L}\right)>P_{1}^{*}$ and $P_{2}^{\min }\left(\bar{P}_{R}\right)<P_{2}^{*}$. The remainder of the proof is exactly analogous. 
one $i=1,2$. This concludes the proof.

Proof of Proposition 3. First, suppose $P_{L}=P_{R}=P_{1}^{*}$ and $x_{1}>0.5$. (Recall from Lemma 4 that $x_{1}>0.5$ is necessary for $P_{L}=P_{R}=P_{1}^{*}$ to be an equilibrium.) For party $R$, any deviation to the left of $P_{1}^{*}$ is not beneficial because it loses both diehards and (at least) a mass $0.5-x_{2}=x_{1}-0.5>0$ of $M$-voters. Similarly, any deviation of party $L$ to the right of $P_{1}^{*}$ is not beneficial because it loses both diehards and all $M$-voters. Now let us consider three other possible scenarios for deviating behavior from $P_{L}=P_{R}=P_{1}^{*}$, starting with party $R$. If party $R$ moves to the right of $P_{1}^{*}$, it loses all $M$-voters, i.e., the best is to go to $\bar{P}_{R}$. We already know from the proof of Lemma 4 that this does not pay if $F_{R}\left(\bar{P}_{R}-P_{1}^{*}\right) n_{R}<0.5$, which is implied by presumption $F_{R}\left(\bar{P}_{R}-P_{2}^{*}\right) n_{R} \leq 0.5$ under assumption A2. Now, we turn to party $L$. Consider first a deviation of party $L$ to the left of $P_{2}^{\min }\left(P_{1}^{*}\right)$. (Note that $P_{2}^{\min }\left(P_{1}^{*}\right)<P_{1}^{*}$.) Since this implies a loss of all $M$-voters, the best is to go to $\bar{P}_{L}$. We already know from the proof of Lemma 4 that this does not raise the payoff of party $L$ if $F_{L}\left(P_{1}^{*}-\bar{P}_{L}\right) n_{L} \leq 0.5$, as presumed. Finally, consider the case in which party $L$ deviates to a point $P_{L} \in\left(P_{2}^{\min }\left(P_{1}^{*}\right), P_{1}^{*}\right)$. In this case party $L$ will get support from exactly a mass $x_{2}=1-x_{1}$ of $M$-individuals. Since the best is to go as far to the left as possible while retaining these $M$-voters, $P_{L}$ is set slightly above $P_{2}^{\min }\left(P_{1}^{*}\right)$. This will not raise the payoff of party $L$ if and only if $0.5+\left[1-F_{L}\left(P_{1}^{*}-\bar{P}_{L}\right)\right] n_{L} \geq 1-x_{1}+\left[1-F_{L}\left(P_{2}^{\min }\left(P_{1}^{*}\right)-\bar{P}_{L}\right)\right] n_{L}$, which is equivalent to $x_{1} \geq \bar{x}\left(n_{L}, \bar{P}_{L}, P_{1}^{*}\right) \in(0.5,1)$. Observing the uniqueness result in Lemma 5 , this confirms part (i).

To prove part (ii), suppose $P_{L}=P_{R}=P_{2}^{*}$ and $x_{2}>0.5$, i.e., $x_{1}<0.5$. For similar reasons as above, any deviation of party $L$ to the right of $P_{2}^{*}$ and any deviation of party $R$ to the left of $P_{2}^{*}$ is not profitable. Moreover, analogously to the previous case, it is easy to show that, by presumption, it does not pay for party $L$ to deviate in any other way. For party $R$, any deviation to the right of $P_{1}^{\max }\left(P_{2}^{*}\right)$ is equally unprofitable. (Note that $P_{1}^{\max }\left(P_{2}^{*}\right)>P_{2}^{*}$.) Finally, consider the remaining deviation for party $R$, i.e., $P_{R} \in$ $\left(P_{2}^{*}, P_{1}^{\max }\left(P_{2}^{*}\right)\right)$. Setting $P_{R}$ slightly below $P_{1}^{\max }\left(P_{2}^{*}\right)$ does not raise the payoff for party 
$R$ if and only if $0.5+\left[1-F_{R}\left(\bar{P}_{R}-P_{2}^{*}\right)\right] n_{R} \geq x_{1}+\left[1-F_{R}\left(\bar{P}_{R}-P_{1}^{\max }\left(P_{2}^{*}\right)\right)\right] n_{R}$, which is equivalent to $x_{1} \leq \underline{x}\left(n_{R}, \bar{P}_{R}, P_{2}^{*}\right) \in(0,0.5)$. Using Lemma 5 , this confirms part (ii).

To prove part (iii), first, note that presumptions $F_{L}\left(P_{1}^{*}-\bar{P}_{L}\right) n_{L} \leq 0.5$ and $F_{R}\left(\bar{P}_{R}-P_{2}^{*}\right) n_{R} \leq 0.5$ imply

$$
F_{L}\left(P_{1}^{\min }\left(\bar{P}_{R}\right)-\bar{P}_{L}\right) n_{L}<0.5 \text { and } F_{R}\left(\bar{P}_{R}-P_{2}^{\max }\left(\bar{P}_{L}\right)\right) n_{R}<0.5
$$

since $P_{1}^{\min }\left(\bar{P}_{R}\right)<P_{1}^{*}$ and $P_{2}^{\max }\left(\bar{P}_{L}\right)>P_{2}^{*}$, respectively; moreover, under A2,

$$
F_{L}\left(P_{2}^{\min }\left(\bar{P}_{R}\right)-\bar{P}_{L}\right) n_{L}<0.5 \text { and } F_{R}\left(\bar{P}_{R}-P_{1}^{\max }\left(\bar{P}_{L}\right)\right) n_{R}<0.5
$$

since $P_{2}^{\min }\left(\bar{P}_{R}\right)<P_{2}^{*}<P_{1}^{*}$ and $P_{1}^{\max }\left(\bar{P}_{L}\right)>P_{1}^{*}>P_{2}^{*}$, respectively. Now recall from Lemma 3 together with the proofs of parts (i) and (ii) that, if $x_{1} \in$ $\left(\underline{x}\left(n_{R}, \bar{P}_{R}, P_{2}^{*}\right), \bar{x}\left(n_{L}, \bar{P}_{L}, P_{1}^{*}\right)\right)$, the only candidate for a Nash equilibrium in pure strategies is $P_{y}=\bar{P}_{y}, y=L, R$. Moreover, recall from the proof of Lemma 5 that for $P_{y}=\bar{P}_{y}, y=L, R$, to be a Nash equilibrium, $F_{L}\left(P_{i}^{\min }\left(\bar{P}_{R}\right)-\bar{P}_{L}\right) n_{L} \geq 0.5$ or $F_{R}\left(\bar{P}_{R}-P_{i}^{\max }\left(\bar{P}_{L}\right)\right) n_{R} \geq 0.5$ must hold for at least one $i=1,2$. However, it is impossible that these conditions hold if both (A.11) and (A.12) are fulfilled. This concludes the proof.

Proof of Proposition 4. The second part of the proposition follows immediately from standard existence theorems of Nash equilibrium, when the strategy space is finite. We thus turn to prove the first part of Proposition 4. Consider first the scenario described by part (i) of Proposition 3. Obviously, any Nash equilibrium in the continuum case is also Nash equilibrium with a grid. However, we need to ensure that no other Nash equilibrium exists. For any pair of strategies, $\left(P_{L}, P_{R}\right) \neq\left(P_{1}^{*}, P_{1}^{*}\right)$, we define the following two sets, for party $L$ and $R$, respectively, that describe the 
payoff derived by each party for any possible strategy:

$$
\begin{aligned}
\Pi_{L}\left(P_{R}\right) & \equiv\left\{\pi_{L}\left(P, P_{R}\right) \mid P \in\left[\bar{P}_{L}, \bar{P}_{R}\right]\right\}, \\
\Pi_{R}\left(P_{L}\right) & \equiv\left\{\pi_{R}\left(P_{L}, P\right) \mid P \in\left[\bar{P}_{L}, \bar{P}_{R}\right]\right\} .
\end{aligned}
$$

Let $\bar{\Pi}_{L}\left(P_{R}\right) \equiv \sup \left[\Pi_{L}\left(P_{R}\right)\right]$ and $\bar{\Pi}_{R}\left(P_{L}\right) \equiv \sup \left[\Pi_{R}\left(P_{L}\right)\right]$ denote, correspondingly, the least upper-bounds associated with the two sets. It is easy to verify using our earlier notation that the following holds:

$$
\begin{aligned}
& \bar{\Pi}_{L}\left(P_{R}\right) \in\left\{\pi_{L}\left(\bar{P}_{L}, P_{R}\right), \pi_{L}\left[P_{2}^{\min }\left(P_{R}\right), P_{R}\right]+\frac{x_{2}}{2}, \pi_{L}\left[P_{1}^{\min }\left(P_{R}\right), P_{R}\right]+\frac{x_{1}}{2}\right\}, \\
& \bar{\Pi}_{R}\left(P_{L}\right) \in\left\{\pi_{R}\left(P_{L}, \bar{P}_{R}\right), \pi_{R}\left[P_{L}, P_{2}^{\max }\left(P_{L}\right)\right]+\frac{x_{2}}{2}, \pi_{R}\left[P_{L}, P_{1}^{\max }\left(P_{L}\right)\right]+\frac{x_{1}}{2}\right\} .
\end{aligned}
$$

Let $H_{L}\left(P_{L}, P_{R}\right) \equiv \bar{\Pi}_{L}\left(P_{R}\right)-\pi_{L}\left(P_{L}, P_{R}\right)$ and $H_{R}\left(P_{L}, P_{R}\right) \equiv \bar{\Pi}_{R}\left(P_{L}\right)-\pi_{R}\left(P_{L}, P_{R}\right)$ denote the upper-bound gains of deviating from $P_{L}$ and $P_{R}$ for party $L$ and $R$, respectively, and let $\bar{H}\left(P_{L}, P_{R}\right) \equiv \max \left[H_{L}\left(P_{L}, P_{R}\right), H_{R}\left(P_{L}, P_{R}\right)\right]$. We need to show that any $\left(P_{L}, P_{R}\right) \neq\left(P_{1}^{*}, P_{1}^{*}\right)$ does not form a Nash equilibrium for a sufficiently fine grid. By construction, and by the definition of equilibrium, $\bar{H}\left(P_{L}, P_{R}\right)>0$. We will separate now between two cases.

Case 1: Consider first the case in which either $\bar{H}\left(P_{L}, P_{R}\right)=H_{L}\left(P_{L}, P_{R}\right)$ and $\bar{\Pi}_{L}\left(P_{R}\right)=\pi_{L}\left(\bar{P}_{L}, P_{R}\right)$, or $\bar{H}\left(P_{L}, P_{R}\right)=H_{R}\left(P_{L}, P_{R}\right)$ and $\bar{\Pi}_{R}\left(P_{L}\right)=\pi_{R}\left(P_{L}, \bar{P}_{R}\right)$. In such a case, it is easy to verify, as $\bar{P}_{L}$ and $\bar{P}_{R}$ are part of the grid, that this does not form equilibrium. We turn next to the other, more complicated case.

Case 2: The other possible scenarios can be described as a union of two sets (defined for party $L$ and $R$, respectively). Let $\Theta=\Theta_{L} \cup \Theta_{R}$, where

$$
\begin{aligned}
\Theta_{L}\left(P_{L}, P_{R}\right) & \equiv\left\{H_{L}\left(P_{L}, P_{R}\right) \mid H_{L}\left(P_{L}, P_{R}\right)=\bar{H}\left(P_{L}, P_{R}\right) \text { and } \bar{\Pi}_{L}\left(P_{R}\right) \neq \pi_{L}\left(\bar{P}_{L}, P_{R}\right)\right\}, \\
\Theta_{R}\left(P_{L}, P_{R}\right) & \equiv\left\{H_{R}\left(P_{L}, P_{R}\right) \mid H_{R}\left(P_{L}, P_{R}\right)=\bar{H}\left(P_{L}, P_{R}\right) \text { and } \bar{\Pi}_{R}\left(P_{L}\right) \neq \pi_{R}\left(P_{L}, \bar{P}_{R}\right)\right\} .
\end{aligned}
$$


Denote by $\underline{\Theta} \equiv \inf [\Theta]$ the largest lower bound of the set $\Theta$. By construction $\Theta \geq 0$. We turn next to prove that $\underline{\Theta}>0$. Assume by negation that $\Theta=0$. This implies that, for any $\varepsilon>0$, there exists a pair $\left(P_{L}, P_{R}\right)$ such that $\bar{H}\left(P_{L}, P_{R}\right) \in \Theta$ and $\bar{H}\left(P_{L}, P_{R}\right) \in(0, \varepsilon)$. Consider an arbitrary small $\varepsilon>0$, and without loss in generality, let $\bar{H}\left(P_{L}, P_{R}\right)=H_{L}\left(P_{L}, P_{R}\right)=\varepsilon^{\prime}<\varepsilon$. If $\varepsilon$ is small, the gain from deviation necessarily derives from an increase in the support of diehard leftists, thus $P_{L}$ necessarily lies in a small neighborhood to the right of either $P_{2}^{\min }\left(P_{R}\right)$ or $P_{1}^{\min }\left(P_{R}\right)$. For concreteness and with no loss in generality, assume the latter, namely, party $L$ sets its policy slightly above the point at which $M$-voters with perception $\hat{S}=S_{1}$ are just indifferent between the platforms of the two parties. Thus, $\varepsilon^{\prime}=\left[F_{L}\left(P_{L}-\bar{P}_{L}\right)-F_{L}\left(P_{1}^{\min }\left(P_{R}\right)-\bar{P}_{L}\right)\right] n_{L}$, which can be rewritten as $\varepsilon^{\prime}=$ $n_{L} \int_{P_{1}^{\min }\left(P_{R}\right)}^{P_{L}} f_{L}\left(P-\bar{P}_{L}\right) d P$ (recall that $f_{L}$ is the density of the distribution of voting utility $\gamma$ for leftist diehards). Hence, $\varepsilon^{\prime} \geq n_{L}\left[P_{L}-P_{1}^{\min }\left(P_{R}\right)\right] f_{L}^{\min }$, where the min superscript refers to the smallest density in the support (which is well defined by the continuity of $f_{L}$ and the fact that the policy space is bounded), implying $x \equiv P_{L}-P_{1}^{\min }\left(P_{R}\right) \leq \varepsilon^{\prime} /\left[n_{L} f_{L}^{\min }\right]$. The infimum distance (from $P_{R}$ ) that party $R$ has to shift its policy in order to attract the $M$-voters with perception $\hat{S}=S_{1}$ (recall that the minimal measure of such voters is $1 / K)$ is given by $P_{R}-P_{1}^{\max }\left(P_{L}\right)$, which by substitution may be rewritten as $Q(x)=P_{R}-P_{1}^{\max }\left(x+P_{1}^{\min }\left(P_{R}\right)\right)$. It is easy to verify that $Q(0)=0$. Furthermore, $Q(\cdot)$ is increasing and continuous. Thus, $Q\left(P_{L}-P_{1}^{\min }\left(P_{R}\right)\right) \leq Q\left(\varepsilon^{\prime} /\left[n_{L} f_{L}^{\min }\right]\right)$. By construction, it follows that $H_{R}\left(P_{L}, P_{R}\right) \geq$ $1 / K-n_{R} \int_{P_{R}-Q\left(P_{L}-P_{1}^{\min }\left(P_{R}\right)\right)}^{P_{R}} f_{R}\left(\bar{P}_{R}-P_{R}\right) d P$. However, using the fact that $Q\left(P_{L}-\right.$ $\left.P_{1}^{\min }\left(P_{R}\right)\right) \leq Q\left(\varepsilon^{\prime} /\left[n_{L} f_{L}^{\min }\right]\right)$ and denoting $f_{R}^{\max }$ is the largest density in the support of $f_{R}$, we obtain

$$
\varepsilon^{\prime}=H_{L}\left(P_{L}, P_{R}\right) \geq H_{R}\left(P_{L}, P_{R}\right) \geq \frac{1}{K}-Q\left(\frac{\varepsilon^{\prime}}{n_{L} f_{L}^{\min }}\right) n_{R} f_{R}^{\max } .
$$

For $\varepsilon^{\prime}=0$, as $Q(0)=0$, this inequality is violated, i.e., $H_{L}\left(P_{L}, P_{R}\right)<H_{R}\left(P_{L}, P_{R}\right)$. By virtue of continuity, this holds for sufficiently small $\varepsilon^{\prime}>0$. This establishes that $\underline{\Theta}>0$ by contradiction. We can repeat the same argument for the other two scenarios 
[described by parts (ii) and (iii) of Proposition 3] and define by $d_{i}, d_{i i}$ and $d_{i i i}$, the largest lower bounds, for each scenario, respectively (with $d_{i}=\underline{\Theta}$ ). We further let $d=\min \left(d_{i}, d_{i i}, d_{i i i}\right)>0$. We conclude that any grid including the bliss points $\left(P_{i}^{*}\right.$, $i=1,2)$ and the end points $\left(\bar{P}_{L}\right.$ and $\left.\bar{P}_{R}\right)$, such that the distance between two adjacent points is lower than $d$, maintains the results of Proposition 3. This completes the proof.

Proof of Lemma 6. We start with $x_{1}=2 / 3$, first showing that there exists no Nash equilibrium in pure strategies for the game described in Tab. 4. Consider first party $L$. If party $R$ proposes the platform $P_{1}^{*}$, party $L$ 's best response would be to propose $\bar{P}_{L}$ if and only if $n_{L}+1 / 6>n_{L} / 4+1 / 2$, which holds if and only if $n_{L}>4 / 9$. By our parametric restrictions this indeed holds. However, when party $L$ proposes $\bar{P}_{L}$, party $R$ 's best response is $P_{1}^{*}$ if and only if $n_{R} / 2+5 / 6>n_{R}+2 / 3$, which holds if and only if $n_{R}<1 / 3$. This, however, violates our parametric assumption that $n_{R}>4 / 9$. Suppose next, that party $R$ proposes the platform $\bar{P}_{R}$. Party $L$ 's best response would be to propose $P_{1}^{*}$ if and only if $n_{L} / 4+1>n_{L}+1 / 3$, which holds if and only if $n_{L}<8 / 9$. By virtue of our parametric assumption, $n_{L}<2 / 3$, hence this indeed holds true. Turning next to party $R$, it is easy to verify that its best response when $P_{1}^{*}$ is proposed by party $L$, is to propose $P_{1}^{*}$, as $n_{R} / 2+1 / 2>n_{R}$, because $n_{R}<2 / 3$. We conclude that no Nash equilibrium in pure strategies exists for the case $x_{1}=2 / 3$.

We next turn to characterize the equilibrium in mixed strategies. Denote by $E N_{y}(P)$ the expected utility derived by party $y=L, R$ when proposing the platform $P$ and when the other party sticks to its equilibrium (mixed) strategy. From Tab. 4, it follows that:

$$
\begin{aligned}
& E N_{L}\left(P_{1}^{*}\right)=r \cdot\left(\frac{n_{L}}{4}+\frac{1}{2}\right)+(1-r) \cdot\left(\frac{n_{L}}{4}+1\right) \\
& E N_{L}\left(\bar{P}_{L}\right)=r \cdot\left(n_{L}+\frac{1}{6}\right)+(1-r) \cdot\left(n_{L}+\frac{1}{3}\right) \\
& E N_{R}\left(P_{1}^{*}\right)=l \cdot\left(\frac{n_{R}}{2}+\frac{1}{2}\right)+(1-l) \cdot\left(\frac{n_{R}}{2}+\frac{5}{6}\right)
\end{aligned}
$$




$$
E N_{R}\left(\bar{P}_{R}\right)=l \cdot n_{R}+(1-l) \cdot\left(n_{R}+\frac{2}{3}\right)
$$

Equating (A.13) and (A.14) (for party $L)$ and (A.15) and (A.16) (for party $R$ ), respectively, and following some algebraic manipulations confirms the first part of Lemma 6. For $x_{1}=1 / 3$ the result follows by symmetry.

Proof of Lemma 7. Recall, from the proof of Lemma 2, the definition $p_{i, k}=$ $\operatorname{prob}\left\{z=\left(S_{i}, k / K\right)\right\}$, where $k=0,1,2,3$ for $K=3$. Using the symmetry property,

$$
\begin{aligned}
E(u)= & p_{1,1}\left\{p\left(n_{R}, n_{L}\right) u\left(\bar{P}_{L}, S_{1}\right)+\left[1-p\left(n_{R}, n_{L}\right)\right] u\left(P_{2}^{*}, S_{1}\right)\right\}+ \\
& p_{1,2}\left\{p\left(n_{L}, n_{R}\right) u\left(\bar{P}_{R}, S_{1}\right)+\left[1-p\left(n_{L}, n_{R}\right)\right] u\left(P_{1}^{*}, S_{1}\right)\right\}+ \\
& p_{1,3} u\left(P_{1}^{*}, S_{1}\right)+p_{2,0} u\left(P_{2}^{*}, S_{2}\right)+ \\
& p_{2,1}\left\{p\left(n_{R}, n_{L}\right) u\left(\bar{P}_{L}, S_{2}\right)+\left[1-p\left(n_{R}, n_{L}\right)\right] u\left(P_{2}^{*}, S_{2}\right)\right\}+ \\
& p_{2,2}\left\{p\left(n_{L}, n_{R}\right) u\left(\bar{P}_{R}, S_{2}\right)+\left[1-p\left(n_{L}, n_{R}\right)\right] u\left(P_{1}^{*}, S_{2}\right)\right\} .
\end{aligned}
$$

Employing Lemma 2 and rearranging confirms Lemma 7 [with Const $=p_{1,1} u\left(P_{2}^{*}, S_{1}\right)+$ $\left.p_{1,2} u\left(P_{1}^{*}, S_{1}\right)+p_{1,3} u\left(P_{1}^{*}, S_{1}\right)+p_{2,0} u\left(P_{2}^{*}, S_{2}\right)+p_{2,1} u\left(P_{2}^{*}, S_{2}\right)+p_{2,2} u\left(P_{1}^{*}, S_{2}\right)\right]$.

\section{B. A Positive Measure of Policy Reform Stickiness}

A natural positive measure for policy reform stickiness is given by the mean time between switches, namely the mean time it takes to switch between policies. Note that in the monopolistic case, there are two policies in the equilibrium support (in the competitive case of section 4, there are four elements, so one can apply the same technique with the required modifications). We turn to calculate the measure.

Recall the $c$ measures the switching cost from implementing $P_{2}^{\min }\left(\bar{P}_{R}\right)$ to implementing $P_{1}^{\min }\left(\bar{P}_{R}\right)$. Denote by $\tilde{k}$ the largest $k$, such that $k / K$ is lower than $c$. This describes a transition state, namely a state in which a policy switch has a positive probability to occur. In the long run, the frequency of the event describing a switching from $P_{2}^{\min }\left(\bar{P}_{R}\right)$ to $P_{1}^{\min }\left(\bar{P}_{R}\right)$, denoted by $\phi_{2,1}$, is therefore given by (employing the notation used in the proof of Lemma 2): $\phi_{2,1}=p_{1, \tilde{k}} q+p_{2, \tilde{k}}(1-q)$. 
In words, there are two possible scenarios that may yield a policy switch from $P_{2}^{\min }\left(\bar{P}_{R}\right)$ to $P_{1}^{\min }\left(\bar{P}_{R}\right)$. The first is the case where the economy is in a transition state and $S_{1}$ prevails, requiring (for a switch to take place) that the economy will remain in $S_{1}$. The other scenario is the one in which $S_{2}$ prevails, and a shift to $S_{1}$ is required for a switch to occur. By a symmetric argument, it follows that the frequency of switching from $P_{1}^{\min }\left(\bar{P}_{R}\right)$ to $P_{2}^{\min }\left(\bar{P}_{R}\right)$ is given by $\phi_{1,2}=p_{1, \tilde{k}+1}(1-q)+p_{2, \tilde{k}+1} q$.

The long run frequency of a switch [either from $P_{2}^{\min }\left(\bar{P}_{R}\right)$ to $P_{1}^{\min }\left(\bar{P}_{R}\right)$ or vice versa) is thus given by $\phi \equiv \phi_{2,1}+\phi_{1,2}$. Substitution from (6) and (7) yield:

$$
\phi=\frac{1-q}{1+(K-1)(1-q)} .
$$

For any finite horizon, $T$, of the economy, the mean time between switches, denoted by $M T B S$, may be calculated by $M T B S=T /(1+N O S)$, where NOS denotes the number of switches. When $T$ goes to infinity, $N O S / T \rightarrow \phi$, and $M T B S \rightarrow 1 / \phi=$ $(1-q)^{-1}+K-1$. Obviously, as the friction in information rises ( $K$ increases) and the degree of persistence rises ( $q$ rises) the mean time between switches rises.

\section{References}

Abramowitz, Alan I. and Kyle L. Saunders (1998). Ideological Realignment in the US Electorate. Journal of Politics 60, 634-652.

Adams, James and Samuel Merrill, III (2003). Voter Turnout and Candidate Strategies in American Elections, Journal of Politics 65, 161-189.

Alesina, Alberto (1988). Credibility and Policy Convergence in a Two-Party System with Rational Voters, American Economic Review 78, 796-805.

Alesina, Alberto and Roberto Perotti (1996). Fiscal Discipline and the Budget Process, American Economic Review Papers and Proceedings 86, 401-407.

Bartels, Larry M. (2000). Partisanship and Voting Behavior, 1952-1996, American Journal of Political Science 44, 35-50.

Campbell, Angus, Philip Converse, Warren Miller, and Donald Stokes (1960). The 
American Voter, Chicago: University of Chicago Press.

Carmines, Edward G. and Harold W. Stanley (1992). The Transformation of the New Deal Party System: Social Groups, Political Ideology, and Changing Partisanship Among Northern Whites, 1972-1988, Political Behavior 14, 213-237.

Carroll, Christopher D. (2003). Macroeconomic Expectations of Households and Professional Forecasts, Quarterly Journal of Economics 118, 269-298.

Cukierman, Alex and Mariano Tommasi (1998a). When Does It Take a Nixon to Go to China?, American Economic Review 88, 180-197.

Cukierman, Alex and Mariano Tommasi (1998b). Credibility of Policymakers and of Economic Reforms, in: Sturzenegger, F. and M. Tommasi (eds.), The Political Economy of Reform, Cambridge, MA: MIT Press.

Di Tella, Rafael and Robert MacCulloch (2004). Partisan Social Happiness, Review of Economic Studies (forthcoming).

Dixit, Avinash and John Londregan (1998). Ideology, Tactics, and Efficiency in Redistributive Politics, Quarterly Journal of Economics 113, 497-529.

Downs, Anthony (1957). An Economic Theory of Democracy, New York: Harper \& Row.

Drazen, Allan (2000). Political Economy in Macroeconomics, Princeton University Press, Princeton.

Esteban, Joan-María and Debraj Ray (1994). On the Measurement of Polarization, Econometrica 62, 819-851.

Fernandez, Raquel and Dani Rodrik (1991). Resistance to Reform: Status Quo Bias in the Presence of Individual-Specific Uncertainty, American Economic Review 81, 1146-55.

Fiorina, Morris P. (1999). Whatever Happened to the Median Voter?, Stanford University (mimeo).

Franklin, Charles H. (1992). Measurement and Party Identification, Political Behavior 3, 297-309.

Gabaix, Xavier, David Laibson, Guillermo Moloche and Stephen Weinberg (2003). 
The Allocation of Attention: Theory and Evidence, MIT, Department of Economics Working Paper 03-31.

Greene, Steven (2004). Social Identity Theory and Party Identification, Social Science Quarterly 85, 136-153.

Grossman, Gene M. and Elhanan Helpman (1996). Electoral Competition and Special Interest Politics, Review of Economic Studies 63, 265-286.

Grossman, Gene M. and Elhanan Helpman (2001). Special Interest Politics, Cambridge, Mass.: MIT Press.

Mael, Fred, and Lois Tetrick (1992). Identifying Organizational Identification, Educational and Psychological Measurement 54, 813-24.

Mankiw, N. Gregory and Ricardo Reis (2002). Sticky Information versus Sticky Prices: A Proposal to Replace the New Keynesian Phillips Curve, Quarterly Journal of Economics 117, 1295-1328.

NES (2002). Time Series Data, Center for Political Studies, University of Michigan, Ann Arbor, MI, www.umich.edu/ nes.

Olson, Mancur (1982). The Rise and Decline of Nations, New Haven, CT: MIT Press.

Persson, Torsten and Guido Tabellini (2000). Political Economics. Explaining Economic Policy, MIT Press, Cambridge, MA.

Plane, Dennis L. and Joseph Gershtenson (2004). Candidates' Ideological Locations, Abstention, and Turnout in U.S. Senate Elections, Political Behavior (forthcoming).

Rogoff, Kenneth and Anne Sibert (1988). Elections and Macroeconomic Policy Cycles, Review of Economic Studies 55, 1-16.

Schreckhise, William D. and Todd G. Shields (2003). Ideological Realignment in the Contemporary U.S. Electorate Revisited, Social Science Quarterly 84, 596-612.

Schultz, Christian (1996). Polarization and Inefficient Policies, Review of Economic Studies 63, 331-344.

Shachar, Ron (2003). Party Loyalty as Habit Formation, Journal of Applied 
Econometrics 18, 251-269.

Sims, Christopher A. (2003). Implications of Rational Inattention, Journal of Monetary Economics 50, 665-690.

Zipp, John F (1985). Perceived Representativess and Voting: An Assessment of the Impact of "Choices" vs. "Echoes", American Political Science Review 79, 50-61. 


\section{CESifo Working Paper Series}

(for full list see www.cesifo.de)

1213 Hendrik Hakenes and Martin Peitz, Selling Reputation When Going out of Business, June 2004

1214 Heikki Oksanen, Public Pensions in the National Accounts and Public Finance Targets, June 2004

1215 Ernst Fehr, Alexander Klein, and Klaus M. Schmidt, Contracts, Fairness, and Incentives, June 2004

1216 Amihai Glazer, Vesa Kanniainen, and Panu Poutvaara, Initial Luck, Status-Seeking and Snowballs Lead to Corporate Success and Failure, June 2004

1217 Bum J. Kim and Harris Schlesinger, Adverse Selection in an Insurance Market with Government-Guaranteed Subsistence Levels, June 2004

1218 Armin Falk, Charitable Giving as a Gift Exchange - Evidence from a Field Experiment, June 2004

1219 Rainer Niemann, Asymmetric Taxation and Cross-Border Investment Decisions, June 2004

1220 Christian Holzner, Volker Meier, and Martin Werding, Time Limits on Welfare Use under Involuntary Unemployment, June 2004

1221 Michiel Evers, Ruud A. de Mooij, and Herman R. J. Vollebergh, Tax Competition under Minimum Rates: The Case of European Diesel Excises, June 2004

1222 S. Brock Blomberg and Gregory D. Hess, How Much Does Violence Tax Trade?, June 2004

1223 Josse Delfgaauw and Robert Dur, Incentives and Workers' Motivation in the Public Sector, June 2004

1224 Paul De Grauwe and Cláudia Costa Storti, The Effects of Monetary Policy: A MetaAnalysis, June 2004

1225 Volker Grossmann, How to Promote R\&D-based Growth? Public Education Expenditure on Scientists and Engineers versus R\&D Subsidies, June 2004

1226 Bart Cockx and Jean Ries, The Exhaustion of Unemployment Benefits in Belgium. Does it Enhance the Probability of Employment?, June 2004

1227 Bertil Holmlund, Sickness Absence and Search Unemployment, June 2004 
1228 Klaas J. Beniers and Robert Dur, Politicians' Motivation, Political Culture, and Electoral Competition, June 2004

1229 M. Hashem Pesaran, General Diagnostic Tests for Cross Section Dependence in Panels, July 2004

1230 Wladimir Raymond, Pierre Mohnen, Franz Palm, and Sybrand Schim van der Loeff, An Empirically-Based Taxonomy of Dutch Manufacturing: Innovation Policy Implications, July 2004

1231 Stefan Homburg, A New Approach to Optimal Commodity Taxation, July 2004

1232 Lorenzo Cappellari and Stephen P. Jenkins, Modelling Low Pay Transition Probabilities, Accounting for Panel Attrition, Non-Response, and Initial Conditions, July 2004

1233 Cheng Hsiao and M. Hashem Pesaran, Random Coefficient Panel Data Models, July 2004

1234 Frederick van der Ploeg, The Welfare State, Redistribution and the Economy, Reciprocal Altruism, Consumer Rivalry and Second Best, July 2004

1235 Thomas Fuchs and Ludger Woessmann, What Accounts for International Differences in Student Performance? A Re-Examination Using PISA Data, July 2004

1236 Pascalis Raimondos-Møller and Alan D. Woodland, Measuring Tax Efficiency: A Tax Optimality Index, July 2004

1237 M. Hashem Pesaran, Davide Pettenuzzo, and Allan Timmermann, Forecasting Time Series Subject to Multiple Structural Breaks, July 2004

1238 Panu Poutvaara and Andreas Wagener, The Invisible Hand Plays Dice: Eventualities in Religious Markets, July 2004

1239 Eckhard Janeba, Moral Federalism, July 2004

1240 Robert S. Chirinko, Steven M. Fazzari, and Andrew P. Meyer, That Elusive Elasticity: A Long-Panel Approach to Estimating the Capital-Labor Substitution Elasticity, July 2004

1241 Hans Jarle Kind, Karen Helene Midelfart, Guttorm Schjelderup, Corporate Tax Systems, Multinational Enterprises, and Economic Integration, July 2004

1242 Vankatesh Bala and Ngo Van Long, International Trade and Cultural Diversity: A Model of Preference Selection, July 2004

1243 Wolfgang Eggert and Alfons J. Weichenrieder, On the Economics of Bottle Deposits, July 2004

1244 Sören Blomquist and Vidar Christiansen, Taxation and Heterogeneous Preferences, July 2004 
1245 Rafael Lalive and Alois Stutzer, Approval of Equal Rights and Gender Differences in Well-Being, July 2004

1246 Paolo M. Panteghini, Wide vs. Narrow Tax Bases under Optimal Investment Timing, July 2004

1247 Marika Karanassou, Hector Sala, and Dennis J. Snower, Unemployment in the European Union: Institutions, Prices, and Growth, July 2004

1248 Engin Dalgic and Ngo Van Long, Corrupt Local Government as Resource Farmers: The Helping Hand and the Grabbing Hand, July 2004

1249 Francesco Giavazzi and Guido Tabellini, Economic and Political Liberalizations, July 2004

1250 Yin-Wong Cheung and Jude Yuen, An Output Perspective on a Northeast Asia Currency Union, August 2004

1251 Ralf Elsas, Frank Heinemann, and Marcel Tyrell, Multiple but Asymmetric Bank Financing: The Case of Relationship Lending, August 2004

1252 Steinar Holden, Wage Formation under Low Inflation, August 2004

1253 Ngo Van Long and Gerhard Sorger, Insecure Property Rights and Growth: The Roles of Appropriation Costs, Wealth Effects, and Heterogeneity, August 2004

1254 Klaus Wälde and Pia Weiß, International Competition, Slim Firms and Wage Inequality, August 2004

1255 Jeremy S. S. Edwards and Alfons J. Weichenrieder, How Weak is the Weakest-Link Principle? On the Measurement of Firm Owners’ Control Rights, August 2004

1256 Guido Tabellini, The Role of the State in Economic Development, August 2004

1257 François Larmande and Jean-Pierre Ponssard, EVA and the Controllability-congruence Trade-off: An Empirical Investigation, August 2004

1258 Vesa Kanniainen and Jenni Pääkkönen, Anonymous Money, Moral Sentiments and Welfare, August 2004

1259 Panu Poutvaara and Andreas Wagener, Why is the Public Sector More Labor-Intensive? A Distortionary Tax Argument, August 2004

1260 Lars P. Feld and Stefan Voigt, Making Judges Independent - Some Proposals Regarding the Judiciary, August 2004

1261 Joop Hartog, Hans van Ophem, and Simona Maria Bajdechi, How Risky is Investment in Human Capital?, August 2004 
1262 Thomas Eichner and Rüdiger Pethig, Efficient Nonanthropocentric Nature Protection, August 2004

1263 David-Jan Jansen and Jakob de Haan, Look Who's Talking: ECB Communication during the First Years of EMU, August 2004

1264 David F. Bradford, The X Tax in the World Economy, August 2004

1265 Hans-Werner Sinn, Migration, Social Standards and Replacement Incomes. How to Protect Low-income Workers in the Industrialized Countries against the Forces of Globalization and Market Integration, August 2004

1266 Wolfgang Leininger, Fending off one Means Fending off all: Evolutionary Stability in Submodular Games, August 2004

1267 Antoine Bommier and Bertrand Villeneuve, Risk Aversion and the Value of Risk to Life, September 2004

1268 Harrie A. A. Verbon and Lex Meijdam, Too Many Migrants, Too Few Services: A Model of Decision-making on Immigration and Integration with Cultural Distance, September 2004

1269 Thomas Eichner and Rüdiger Pethig, Economic Land Use, Ecosystem Services and Microfounded Species Dynamics, September 2004

1270 Federico Revelli, Performance Rating and Yardstick Competition in Social Service Provision, September 2004

1271 Gerhard O. Orosel and Klaus G. Zauner, Vertical Product Differentiation When Quality is Unobservable to Buyers, September 2004

1272 Christoph Böhringer, Stefan Boeters, and Michael Feil, Taxation and Unemployment: An Applied General Equilibrium Approach, September 2004

1273 Assaf Razin and Efraim Sadka, Welfare Migration: Is the Net Fiscal Burden a Good Measure of its Economics Impact on the Welfare of the Native-Born Population?, September 2004

1274 Tomer Blumkin and Volker Grossmann, Ideological Polarization, Sticky Information, and Policy Reforms, September 2004 